\title{
Residual Deformities of the Maxillofacial Region
}

\author{
Samson Jimson
}

\subsection{Introduction}

A maxillofacial surgeon plays a vital role in not only restoring the structural form of the maxillofacial unit but also aims to restore the pre-traumatic functional status of the patient. Diagnosis, clinical evaluation with enhanced treatment planning and restoration of aesthetics and function is the key for any maxillofacial surgery. However, it is not always possible to achieve the most appropriate results in all cases. It is not uncommon to see failure or mediocre outcomes following maxillofacial trauma surgery. The outcome of the primary treatment may depend on factors such as the extent of the injury/defect, delay in diagnosis/management, improper treatment plan, lack of utilizing modern diagnostic/treatment planning utilities, poor execution of treatment plan and inexperience of the surgeon. These may lead to not expecting the eventful deformities and not coordinating with other specialists to yield the most standard and deserving treatment for the patient with restoration of both form and function [1-3].

Residual deformities are seen following primary treatment of trauma due to one more reason mentioned earlier. Correction of such residual deformities may be challenging to the surgeon but very often a life-changing experience for patients. It is the experience of the surgeon that helps to recognise the challenges ahead in restoring the form and function. Residual deformities are often evaluated by the extent of deformities following primary management. Apart from reasons that may pertain to the experience of the operating surgeon, pathobiology of the healing zone may also contribute to the residual deformities. A variety of such reasons contributes to both soft tissue and hard tissue defects in the maxillofacial unit. This chapter aims to discuss in detail the clinical evaluation, diagnosis, protocols,

\footnotetext{
S. Jimson $(\bowtie)$

Department of Oral and Maxillofacial Surgery, Tagore Dental

College and hospital, Chennai, India

e-mail: jimsons@tagoredch.in
}

management and post-operative care of hard tissue deformities in oral and maxillofacial surgery with emphasis on current trends and future propositions.

\subsubsection{Preventive Wound Management [4]}

Wound management begins right after the soft tissue injury in the primary or acute stage.

Post-traumatic scarring can be reduced considering the following measures:

- Removal of foreign bodies/debris

- Reduce bacterial carriage by copious irrigation

- Judicious debridement to reduce the persistent scarring

- Management of the adjacent tissue with appropriate closure

- Tension free closure, minimising scar formation

- Wound care management by the use of agents that promote healing

- Prophylactic antibiotics in necessary conditions

Soft tissue injuries/scar revision/soft tissue and hard tissue reconstruction related to management of residual deformities have been dealt in detail in respective chapters of this book (refer Chaps. 36, 49, 86 and 88). Wound care and management begin with preventive measures.

\subsubsection{Volume Issues in Deformities [3]}

This section briefly discusses management of volume defects using tissue expanders. Volume issues are to be considered with all excision techniques. Loss of tissue volume due to trauma or contraction of the scar may lead to depression and 
distortions that are more obvious than the original scar. Such loss of tissue may require volume replacement that can be achieved by other techniques. Surgical flaps may be commonly used to fill the tissues. Likewise, biological fillers can also be taken into consideration in managing depressed or irregular areas. Tissue debulking can be done whenever there is an excess of tissue volume.

Two methods of tissue transfer can be opted whenever there is loss of tissue: a free skin graft and a skin flap. A free skin graft of limited thickness involves the complete removal from the donor site and then placement on the recipient site for survival. This type of graft will not survive in avascular recipient sites. A skin flap with underlying subcutaneous tissue will carry its blood supply necessary for the survival of the flap. These skin flaps are further divided into local flaps or distant flaps (from distant sites). Single-stage transfer of flaps may be done with microvascular surgical techniques (Chart 61.1 shows types of soft tissue deformities with relation to the volume defects).

\subsubsection{Minor Loss of Tissue [3]}

- Local flaps should always be considered in case of minor loss of tissue. Facial tissue is naturally the first choice due to the colour and texture for replacement of tissue defects that are not too extensive. In such cases of local flaps, skin bordering the deformity should be raised and rotated into the defect, approximating the scar in a favourable position.

- Small scar defects may not yield a good result with split skin grafts, but full-thickness grafts can potentially give good aesthetic results in the repair of small defects.

- Lower eyelid scarring due to ectropion may be corrected using full-thickness graft (Wolfe's graft) that results in predictable function and aesthetics.

\subsubsection{Major Loss of Tissue [3]}

- Traumatic or gunshot injuries may result in a substantial loss of tissues. Majorly these injuries are associated with loss of soft tissue and skeletal structure.

- The replacement of tissue should involve necessary covering, lining and support to the bone or cartilage.

- Flaps used in all anatomical structures like the antrum, orbit, mouth and nose should have necessary lining epithelium; otherwise it will result in contraction of the tissues and exposure of underlying tissues.

- Complications like nasal airway stenosis, oral stenosis, microsomia and obliterated buccal/labial sulcus may occur.

- A split skin graft may be used in case of nasal or buccal defect.

- Double flap with both inner and outer aspects composed of full-thickness skin or subcutaneous tissue may help to increase the flexibility in case of a cheek flap. In such cases, the extent of fibrosis is decreased and thereby helps in increasing flexibility due to the underlying vascularity.

- Nasal lining may be provided by approximating the adjacent in-turned flaps of skin around the surrounding defects. A split skin graft should be preferred whenever such approximation is not possible. Hard tissue nasal deformities are discussed elsewhere.

- Lip defects may result in loss of larger tissue. Contraction due to lip re-suture may result in the loss of one-third of the available tissue. Local tissue flaps as full-thickness flaps should be considered ahead of tube pedicle flaps. Whenever permissible, it is better to take a full-thickness flap of the cheek or buccal mucosa, rotate it and form a lip and fill the subsequent secondary defect with tube pedicle.
Chart 61.1 Types of soft tissue residual deformities

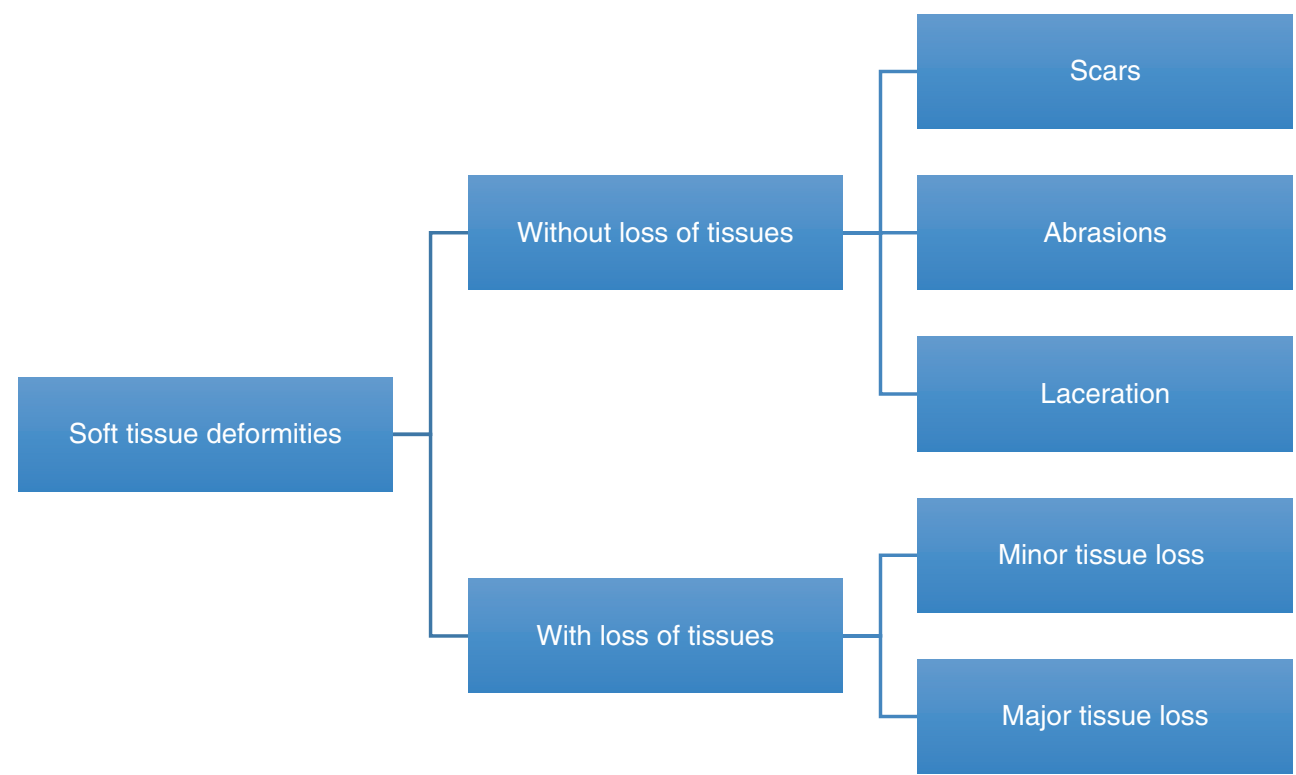

CAssociation of Oral and Maxillofacial Surgeons of India 
- Scar adhesions of the sulcus or obliteration of sulci due to deficient tissues may predispose the difficulty in the construction of a functional and stable prosthesis. The fibrous scar tissue may be excised, or the sulci may be created with dissection followed by insertion of a free split skin graft.

- Palate: Substantial loss of tissue may involve the hard palate, soft palate or both areas. Generally, loss of tissue in the hard palate may be closed with an obturator. Scar tissue associated with the hard tissue defect may be managed by dividing the fibrous scar bands and restoring the residual tissues. Rotational flaps may also be used to close the defects. Tissues from additional sources may be used in the closure by using full-thickness flaps. Two-staged full-thickness flaps from the lateral third of the tongue are used, the base of which is divided after 3 weeks. In case of larger defects, myofascial temporalis flaps may be used with downward rotation, and following osteotomy of the zygomatic arch, it may be passed through a mucosal tunnel to reach the oral cavity. Both the flaps provide better results, but the advantage of the latter is being a singlestaged technique [3].

\subsubsection{Tissue Expanders [4-6]}

Tissue expanders are the advised treatment technique when the loss of tissue or the scar surface areas are larger. It is indicated in revision or excision of scar where local or regional flaps may not be feasible to be used in the immediate reconstruction. Although commonly employed for tissue expansion in forehead and scalp, it may be beneficial for any areas with larger defects. Tissue expansion becomes an ideal choice in the scalp due to its inelasticity. It allows replacement of defects with adjacent surrounding tissue which is similar in colour, texture, adnexal structures and innervation (Fig. 61.1)

Fig. 61.1 Schematic representation of a tissue expander

\subsubsection{Properties of Tissue Expanders} $[4,5,7-9]$

Silastic balloons with self-sealing valves which are used as tissue expanders are implanted beneath the skin.

- These tissue expanders are available in different shapes and sizes and can also be custom-made to fit an irregularly bordered defect.

- It is important to choose an expander of sufficient size to provide the necessary expansive force required for the need in tissue gain for reconstruction.

- The expander has to be 2.5 times that of the scar to be corrected while using a rectangular or crescent-shaped expander. On the other hand, the diameter of the base of the circular expander should be 2.5 times that of the scar to be replaced.

- The expanders must be implanted in a position where ideally a simple advancement, rotation or transposition flaps may be developed later.

- The goal is to have the adjacent healthy tissue expanded and not the scar itself. Hence, the proper placement of the tissue expander is vital.

- Scarred, atrophic areas or sites that have undergone prior radiation therapy are contraindicated.

- Sufficient expander volume must be available.

\subsubsection{Biomechanical Properties}

During the period of tissue expansion, a capsule is formed, and the epidermis is thickened and expanded. Increased mitotic activity is seen evidently using the microscope during the expansion. The dermal thickness, which decreases during the expansion phase, returns to normalcy in 2-3 years. Expanders may also result in decreased adjacent muscle thickness, but without any loss of function. The adipose cells may decrease in number, and subcutaneous thinning may also be seen. Viability of expander is maintained with increased angiogenesis. Bone remodelling may also take place beneath

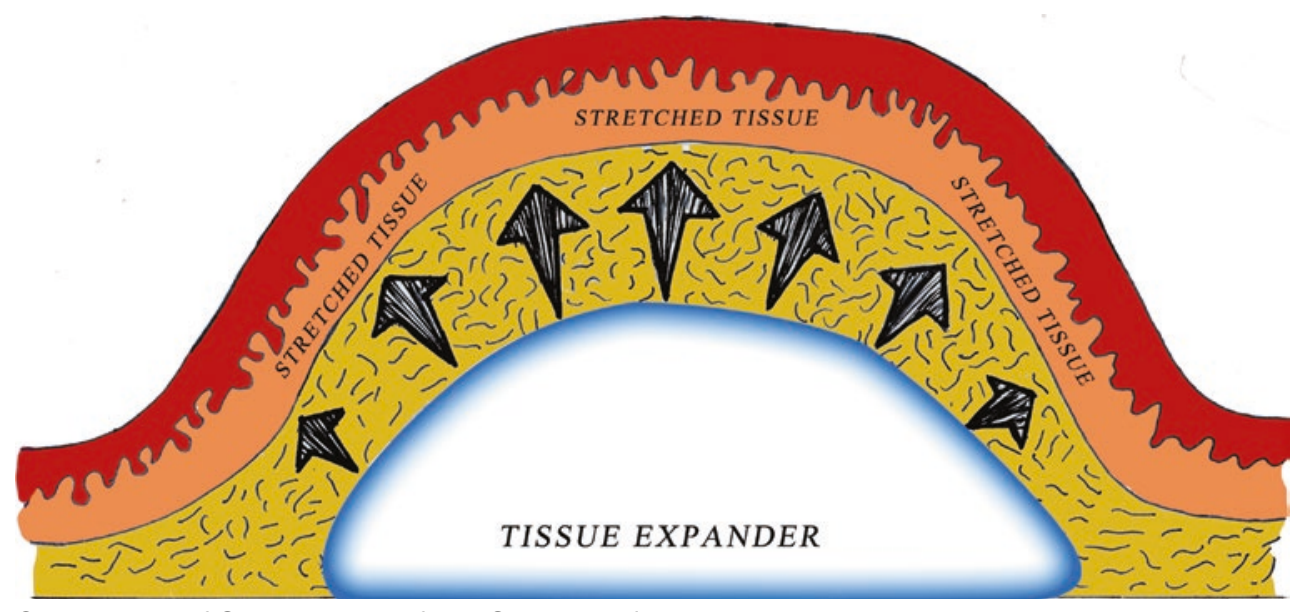

(C)Association of Oral and Maxillofacial Surgeons of India 
the expander. The morphology and number of hair follicles are usually not affected, and hence this is a key in scalp expansion. Treatment duration can be reduced in areas where more than one expander can be placed. The gradual stretching of the tissue over the expanding subcutaneous tissue is called biological creep. Placement of the balloons and allowing a series of inflations and deflations to result in the stretching of the skin are the principles behind tissue expanders. This inherent nature of the skin to expand beyond its natural extensibility is referred to mechanical creep $[4,10]$.

\subsubsection{Technique}

Expanders are implanted by making incisions at the junction of the scar and the healthy tissue. A pocket is made in an avascular fascial plane. Wound closure is done with layers over the expander. $10 \%$ volume of expander may be added at the time of surgery to minimise chances of hematoma formation around the expander. Necrosis of the overlying tissues may occur if any wrinkles are present over the surface of the expanders. If the site allows area for placement for more than one expander, it may reduce the overall treatment duration. Two weeks after placement, the expanders are inflated once or twice in a week. Patient discomfort or blanching over the surface of expander should be observed. Overexpansion of tissue is necessary as there will be a degree of contraction after removal of the expander. Likewise, bony contour changes usually regress without any intervention. The capsule of the expander is released along its margins but is left intact (Fig. 61.2). Generally, a waiting period of 2 weeks should be observed before proceeding to the next stage of the surgery/procedure. This allows the skin tension to reduce before the next stage of the surgery $[4,5]$.

\section{Advantages}

Local usage of tissue by expansion helps in the preservation of the sensation, vascularity and the adnexal structures. This aids well in both aesthetic and functional aspects.

\section{Disadvantages}

- Two operative procedures are usually required.

- Frequent inflation of the expanders.

- A temporarily visible deformity when the expander reaches its full inflation may not be socially acceptable by the patient.

\section{Complications}

- Pain

- Infection

- Implant failure

- Implant exposure

- Necrosis and tissue breakdown leading to exposure of the expander

- Bony erosion below the implant

- Decreased patient compliance and psychological stress for the patient as the expander increases in size creating a transient compromise in aesthetics
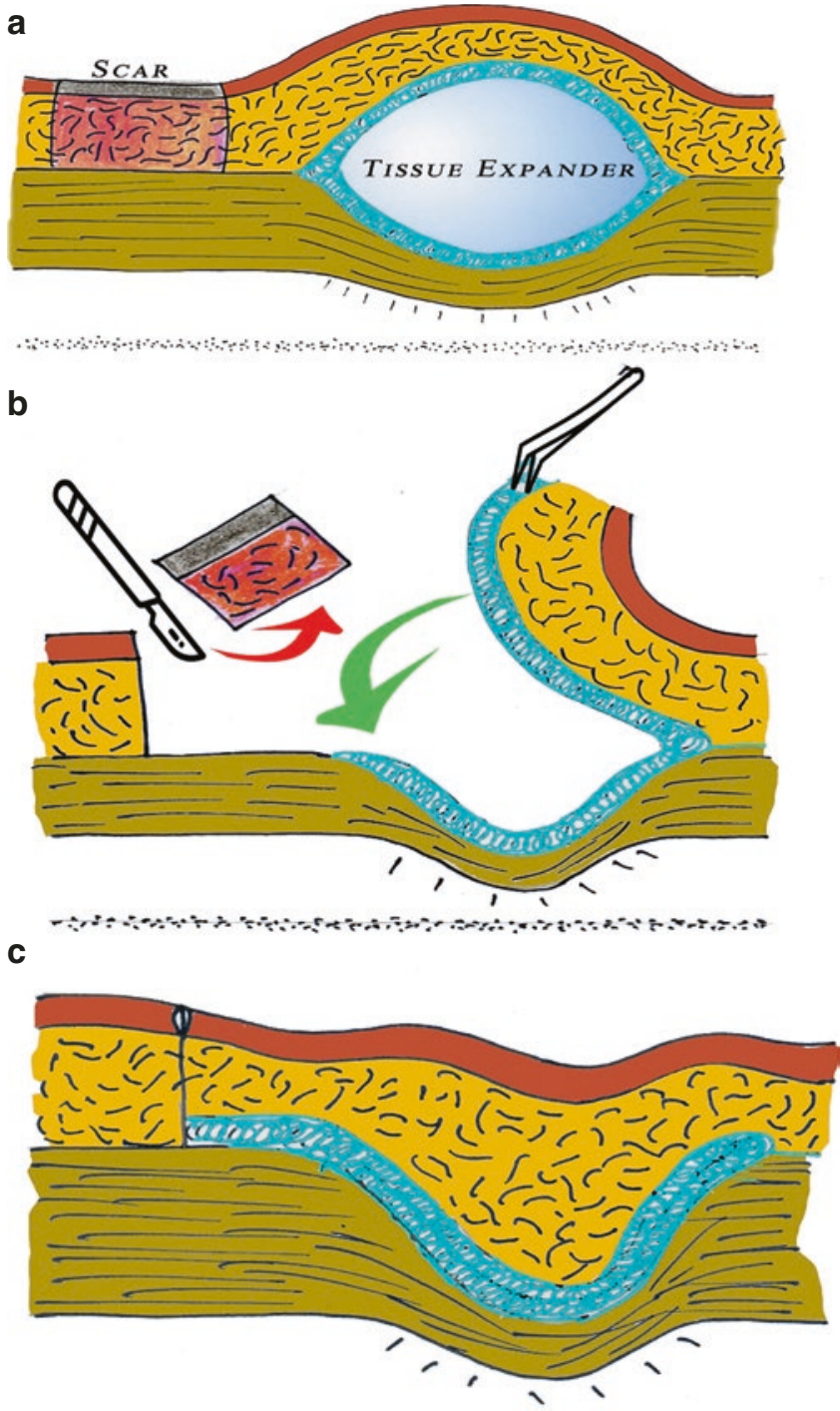

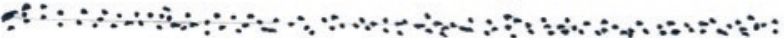
(CAssociation of Oral and Maxillofacial Surgeons of India

Fig. 61.2 Conventional method of tissue expander in management of scar tissue. (a) Expander placed near scar tissue and tissue expansion seen. (b) Adjacent scar tissue removed before closure. (c) Overexpanded tissue closed with adjacent scar tissue removed and the capsule is left intact with release along its margin

This chapter further discusses the use of grafts in residual deformities, management of hard tissue residual deformities and recent advances.

\subsection{Grafts in Residual Deformity}

Soft tissue and hard tissue defects are best managed by the use of grafts. Secondary or residual use of grafts and flaps is essential in restoring the hard tissue and soft tissue defects. The scope of this chapter briefly describes grafts used in residual deformities. This section also outlines the 


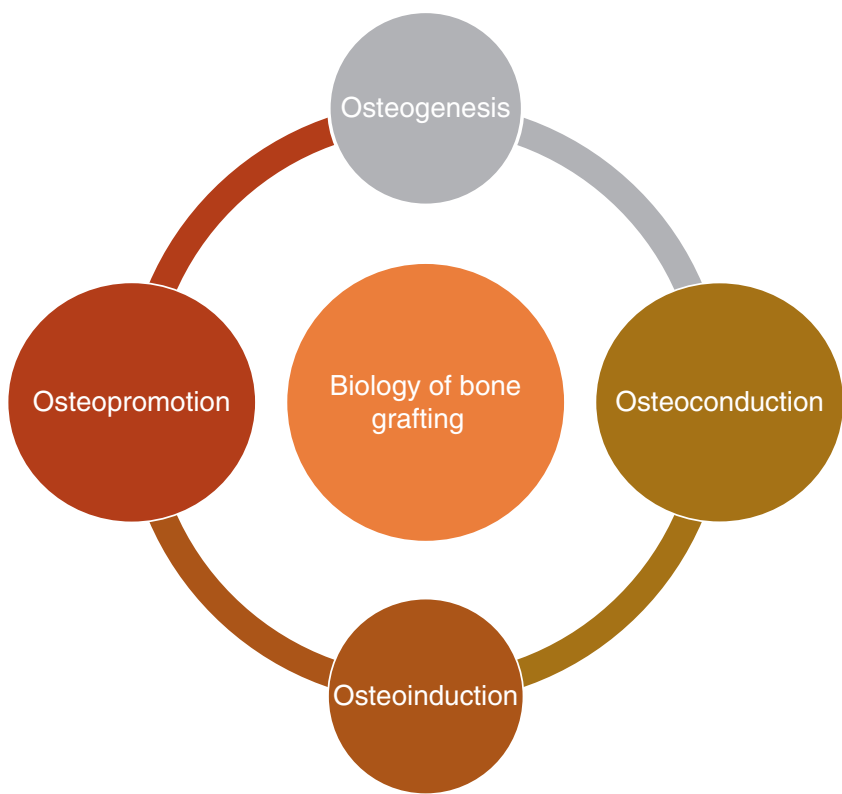

CAssociation of Oral and Maxillofacial Surgeons of India

Chart 61.2 Essentials in biology of bone grafting

biology behind bone grafting and types of bone grafts (Chart 61.2).

\subsubsection{Ideal Characteristics of Bone Graft Material [11]}

- Biocompatible

- Promotes cell differentiation and proliferation

- Less risk of infection

- Non-toxic

- Non-immunogenic

- Maintains volume over time

- Balance in resorption rate and bone formation

- Ability to replace site with new bone growth

\subsubsection{Biology of Bone Grafting}

Biology of bone grafting includes the following rationale [12-17] (Table 61.1):

1. Osteoconduction

2. Osteoinduction

3. Osteopromotion

4. Osteogenesis
Table 61.1 Biology of bone grafting

$\begin{array}{ll}\text { Osteoconduction } & \begin{array}{l}\text { Mechanism in which the graft substance serves as } \\ \text { a scaffold for new bone growth aided by native } \\ \text { bone. Osteoblasts from the source utilize the bone } \\ \text { graft as a structural scaffold on which new bone } \\ \text { generation takes place. A bone graft should be } \\ \text { ideally osteoconductive. Ex: Calcium sulphate, } \\ \text { calcium phosphate cements, ceramics, collagen, } \\ \text { synthetic polymers }\end{array} \\ \text { Osteoinduction } & \begin{array}{l}\text { Mechanism involves stimulation of } \\ \text { osteoprogenitor cells } \rightarrow \text { differentiation into } \\ \text { osteoblasts } \rightarrow \text { formation of new bone. Ex: Bone } \\ \text { morphogenic proteins. It is ideal to have grafts that } \\ \text { are osteoconductive and osteoinductive in nature }\end{array} \\ \text { Ex: DBM (Demineralised Bone Graft), BMPs, } \\ \text { growth factors, genetic therapy }\end{array}$

\subsubsection{Types and Tissue Sources for Grafting} (Table 61.2 and Chart 61.3)

\section{Boyne's Ideal Characteristics of Bone Grafts [18]}

- It should be easily and readily available and should not require additional surgical intervention in a second donor site.

- It should not stimulate any immunological response.

- It should stimulate rapid osteogenesis.

- It should enhance re-vascularisation and neoangiogenesis.

- It should be highly osteoinductive.

- It should be osteoconductive in nature.

- It should not affect or impede bone growth.

Grafts play a major role in primary or secondary/residual management, eventually playing plays a vital role in reconstruction. Bone grafts in residual deformities are ideal to fill volume defects and also aid in reconstruction. Various types and sources of grafts have already been listed (Chart 61.3). 
Table 61.2 Types of bone grafts

\begin{tabular}{|c|c|}
\hline Type & Highlights \\
\hline Autografts & $\begin{array}{l}\text { - Bone grafting from the same individual } \\
\text { - Bone harvesting from nonessential sites } \\
\text { - Less risk of graft rejection } \\
\text { - Osteoconductive, Osteoinductive and osteogenic } \\
\text { - Requires an additional surgical site and risk of } \\
\text { infection, pain and complications in the donor } \\
\text { site } \\
\text { - Gold standard and available in many forms }\end{array}$ \\
\hline Allografts & $\begin{array}{l}\text { - Bone grafting from another individual (Human } \\
\text { donors). Bone is taken from cadavers. Although it } \\
\text { can be from living donors, it is more likely to } \\
\text { come from dead individuals } \\
\text { - Properties may be limited due to preparation and } \\
\text { sterilisation } \\
\text { - Preparation removes risk of antigenicity } \\
\text { - Limited risk of disease transmission } \\
\text { - Osteoinductive } \\
\text { - Gold standard and available in many forms }\end{array}$ \\
\hline $\begin{array}{l}\text { Synthetic } \\
\text { variants }\end{array}$ & $\begin{array}{l}\text { Artificial bone substitutes. Constitutes mineral to } \\
\text { organic matrix ratio close to that of normal human } \\
\text { bone. Grafts not taken from living donors }\end{array}$ \\
\hline Xenografts & Grafts from species other than humans \\
\hline $\begin{array}{l}\text { Alloplastic } \\
\text { grafts }\end{array}$ & $\begin{array}{l}\text { - Strictly a synthetic bone substitute } \\
\text { - Osteoconductive in nature } \\
\text { - No risk of disease transmission } \\
\text { - Unlimited graft options }\end{array}$ \\
\hline Growth factors & $\begin{array}{l}\text { Produced by recombinant DNA technology. } \\
\text { Consists of human growth factors or morphogenic } \\
\text { proteins }\end{array}$ \\
\hline
\end{tabular}

\subsubsection{Bone Grafts in Hard Tissue Residual Deformities}

\subsubsection{Nasal Deformities [19]}

- Bone grafts for nasal deformities can be readily obtained from cranial bone or iliac bone crest. Costochondral and tibial bone grafts have also been used earlier. Cartilage may be harvested from nasal septum. It may also be harvested from conchal bowl of the ear in case of septal bone loss. Osteocartilaginous grafts are discussed in nasal reconstruction in detail.

- Alloplastic materials used in nasal surgeries are silicone, Mersilene mesh, porous polyethylene, proplast, alloderm, etc. The usage depends on the type and size of defects and can be used alone or along with autogenous grafts.

\subsubsection{Orbital Deformities [19]}

- Autogenous bone grafts were earlier considered to be ideal for treatment of orbital floor deformities, but are currently replaced by alloplastic materials. Silastics are currently not considered due to reports of post-operative infection.

Most commonly used alloplastic materials in orbital reconstruction:

- Titanium mesh.

- High-density porous polyethylene implants (e.g. Medpore).

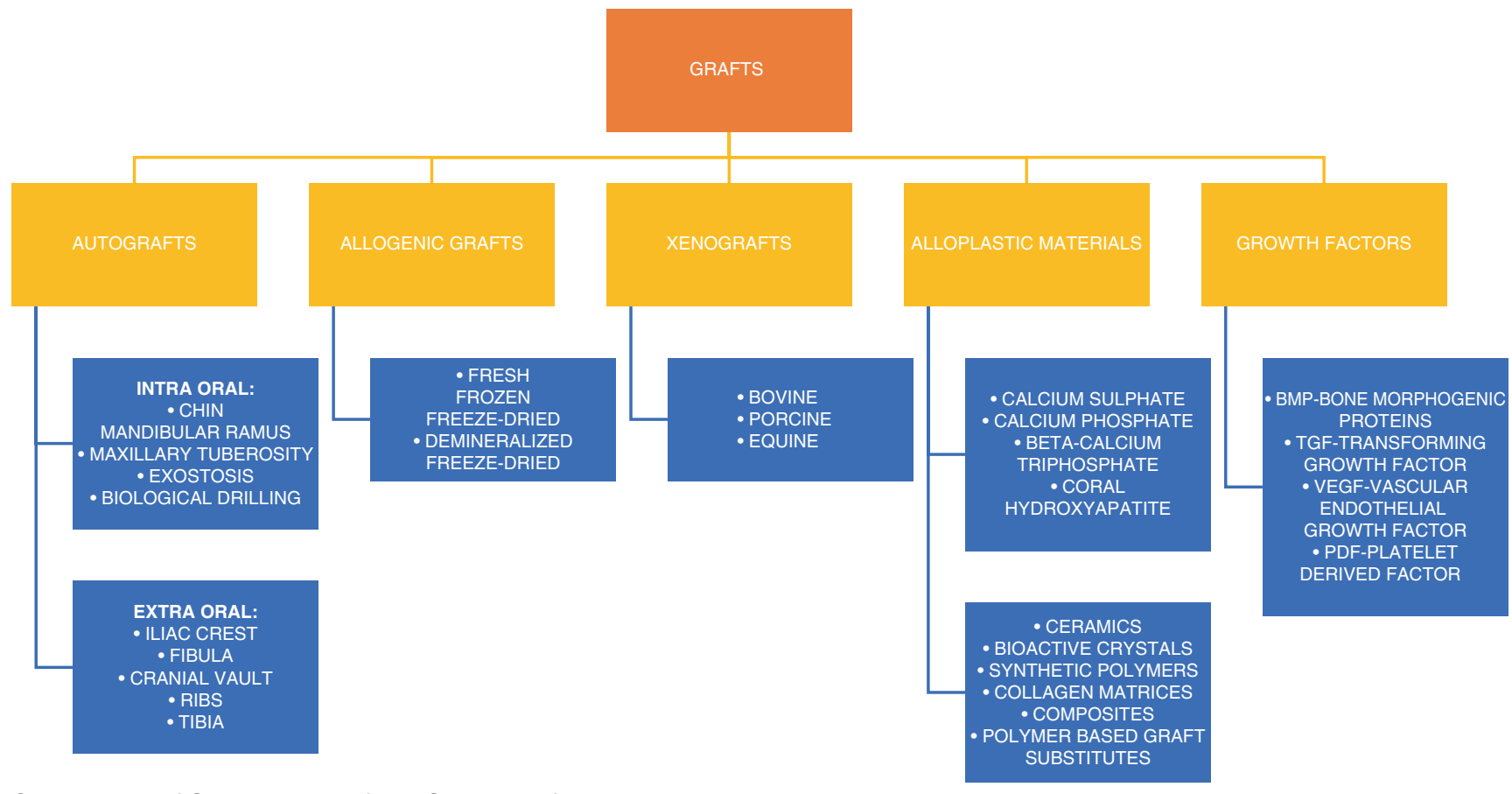

(CAssociation of Oral and Maxillofacial Surgeons of India

Chart 61.3 Sources of bone grafts 
- Orbital floor implants are used by manual adaptation of implants according to the contour of the damaged site. However, custom designed implants with computerguided surgical planning is best utilised in management of late deformities as there is time to assess, plan, design and custom manufacture the precise implants. Orbital titanium implants can also be manufactured by this method.

\subsubsection{Alloplastic Materials [19-24]}

Alloplastic materials have been used in surgeries since 1930s, and newer materials are available since then. Prime advantages of alloplastic materials are reduced donor site morbidity, easily usable, good patient compliance and shorter working time compared to autogenous grafts. Sources and types of graft materials are listed in Chart 61.3.

Goal of Alloplastic Materials

- Biocompatible

- Resistant to infection

- Easy to use

- Cost effective

Their role in maxillofacial reconstruction is still controversial. These porous alloplastic materials are high-density polyethylene implants that are very stable and flexible in nature and also help in new vascular and tissue growth within. This makes alloplasts an essential commodity in management of maxillofacial defects and also in reconstruction.

Alloplastic materials used in the region of defects for reconstruction are available in various forms like titanium mesh, porous polyethylene (Medpor) and PEEK (poly ether ether ketone) which can be customised as needed. Medpore (stock) can be manipulated and adapted in situ according to the defect. It is also possible to make custom-made Medpore, silicone and PEEK with the computer-aided designing. Even though they are known to produce good clinical outcomes, it may be predisposed to infection. Careful handling, understanding patient's history and surgical placement are essential to avoid any complications or to manage any failures. Medpore along with fat grafting may serve to restore the contour as well as the volume. These custom-made implants are widely used in management of defects and deformities as part of maxillofacial reconstruction. Applications of MEDPORE are chin augmentation procedures, correcting congenital deformities and improving aesthetic outcome in nasal, subnasal, paranasal, malar, orbital, and mandibular (angle and body) areas. It is essentially suited for midfacial contouring in patients treated for cleft. The use of these alloplastic materials ideally helps to establish three-dimensional anatomical harmony in correcting defects. Polyether ether ketone (PEEK) is another valuable alloplastic material that precedes with advantages similar to that of Medpore Custommade patient-specific PEEK implants have proven to offer excellent facial rehabilitation. The durability and malleable property of PEEK make it a biomaterial of choice for maxillofacial surgeons with which complex maxillofacial defects following trauma or neoplastic can be corrected. Often, the use of alloplastic materials may be an adjunct or combined with prosthesis to further complete the facial rehabilitation process.

\subsubsection{Use of Grafts in Associated Residual Structural Damages}

Traumatic or iatrogenic reasons causing structural or residual damages are areas of concern during maxillofacial surgery. Important structural damages involving nerve tissues, salivary gland apparatus and nasolacrimal system should be identified and best managed during the primary surgery. If left untreated, secondary or delayed management leads to further complications. It is the skill of the surgeon to carefully carry out the surgery with no or minimal trauma to adjoining structures, and it is experience that will help to predict any relative functional damages and manage it accordingly.

Nerve Injuries: Injuries to the peripheral branches of the trigeminal nerve following maxillofacial trauma or surgery often result in sensory and functional problems. Spontaneous recovery of inferior alveolar nerve and infraorbital nerve after facial fractures depends on a number of factors like age, gender, fracture displacement, site, type of management and time interval between injury and management. Localisation and determination of the pattern of injury of trigeminal nerve are done by careful examination of the neurosensory dysfunction (NSD) of sensory dermatome of trigeminal nerve. It may be very difficult in establishing the exact cause in secondary NSD damages. Such residual defects due to injuries can be from nerve compression due to displaced old fracture segments, laceration due to fracture components, dislocated nerve from a displaced fracture, and compression due to soft tissue oedema or secondary ischemia. Injuries may also be related to crushing, avulsion and partial or total nerve transection [25-28].

Determining the exact aetiology of post-operative residual or secondary NSD damage is difficult, and the best way 
to manage is assessing the damage during the primary surgery. Accessing and operating the site for correction secondarily may itself cause further damage if not handled properly. Nerve grafts can be used in the management of such damages. It involves microsurgical repair of nerve that requires reconstruction of any continuity defect using an autogenous nerve graft (donor site-sural or great auricular nerve). Microsurgical repair helps in improving the clinical outcome in such conditions. Nerve allografts have proven to be successful in improving the neurosensory recovery. Allografts are further beneficial as it alleviates the donor site morbidity. Ichihara et al. suggest the use of alloplastic tubes in short span nerve defects as artificial nerve guides. However, studies need to ascertain their use in long span trigeminal nerve defects. Similar use of autogenous and allogenic grafts is applicable for facial nerve injury as well. The successful outcome of grafts depends on the length/size of the defect and patient factors like age/gender/nutritional status, and it is also important to address factors like previously irradiated sites [29-32].

Salivary Gland/Duct Injuries: Trauma, lacerations, deep injuries and iatrogenic injuries in the parotid region can result in injuries to the important related structures like the buccal branches of facial nerve, Stenson's duct and transverse facial artery and vein. Surgical and non-surgical management of injuries to the salivary gland or its duct is done to improve the clinical outcomes. Non-surgical management includes the use of anti-sialagogues, elastic bandages and reduced oral intake until the defect heals. Microsurgical repair may be done to preserve remaining ductal structures using autologous vein grafts. Reconstruction of the duct is done using autologous vein grafts like saphenous vein, antebrachial vein, facial vein, etc. Alloplastic Gore-Tex has been used, and the outcome was found to be similar to anastomosis in autologous vein grafts in parotid duct reconstruction. Gore-Tex tube carries advantages like decreased graft morbidity and shorter operation time. Timely correction of salivary ducts is important to avoid complications like sialocele, salivary fistula, etc. [33-38].

Nasolacrimal Duct Injury: It is important to reconstruct the nasolacrimal system if damage is seen following orbital or midface trauma. It is similar to other ductal and nerve management. The nasolacrimal duct system can be reconstructed with autogenous and allogenic grafts. Greater saphenous vein can be used as autogenic grafts in such cases. Buccal mucous membrane grafting also shows improved outcomes in removing obstructions in the ducts. Silicone stent intubation is also used in the repair of damaged nasolacrimal duct. Primary management is essential in this condition since delayed management may be difficult to carry out [39-41].

\section{Future of Grafting}

Future in grafting promises advances in gene therapy, tissueengineering, and 3D scaffold. It has created greater perspective with the inclusion of growth factors, stem cells and biological scaffolds that will help in production of laboratoryengineered tissue substitutes in oral and maxillofacial surgery.

Three-dimensional (3D) computed tomography (CT) has brought major changes to visualisation, planning and treatment of maxillofacial defects ever since its introduction. The scanning and surgical planning software have advanced in such a way that a surgeon can meticulously plan a patient-specific protocol to carry out procedures effectively. Preformed and custom printed alloplastic has more accuracy, reduced operative time and a predictable outcome in management. However, conventional implants require intraoperative adaptations and longer duration of operation. All these have been possible with the advances in reconstructive surgeries with CAD-CAM (computer-aided designcomputer-aided modelling) software. Such major advances will lead to further improvement in patientspecific implants (PSI) in the three-dimensional management of defects in reconstructive procedures $[23,24,42,43]$.

\subsection{Hard Tissue Deformities}

Deformities in the maxillofacial bones are due to a variety of causes like pathology, trauma, infection and congenital disabilities. Residual deformities are such defects that are observed even after the primary surgical management and need further cosmetic and functional intervention for an outcome. The size of the defects in the maxillofacial region may vary from small alveolar clefts and nasal deformities to maxilla-mandibulectomy-type defects. Restoration of the deformities to its closest healthy anatomical structure and their essential functioning are the primary goals of any reintervention procedure.

Any defect (size, shape, position or amount) of the osseous structure can be replaced by reconstructive surgery. The aim is to replace it with the missing structure, i.e. the bone. Various types of bone grafts may be used for this purpose. Correction of soft tissue defects needs a complete understanding of the wound healing biology. Likewise, in hard tissue deformities, it is essential to know the bone physiology, immunology and surgical principles to make the reconstruction a successful procedure. 


\subsubsection{Patient Assessment}

Although general rule implies to replace or reconstruct the lost osseous defect, it is important to evaluate every patient thoroughly before proceeding with any intervention. Analysis should include evaluation of hard tissue and associated soft tissues. When accompanied by soft tissue deformities, it is important to treat with caution considering the soft tissue changes over time as well [44].

\subsubsection{Residual Mandibular Deformities} $[3,45-50]$

General Assessment Points for Mandibular Defects:

- Careful and complete clinical examination.

- Necessary radiographs to assess the amount of osseous defects.

- Site and size of the defect to be taken into detailed evaluation. Such evaluation is of utmost importance in mandibular osseous defects.

Causes for Post-traumatic Mandibular Deformities:

- Poor diagnosis

- Improper surgical methods-inadequate reduction and/or fixation

- Infection

- Healing disorders

Residual Deformities in Mandible:

- Causes like trauma, gunshot wounds and infection may result in loss of a portion of the mandible.

- Loss of tissues results in functional and aesthetic concerns. Small deformities may often go unnoticed.

- Loss of a portion of the alveolar process leading to loss of teeth is a less serious complication.

- Malunion of mandibular fractures can often result in serious consequences in occlusion among adults and children. More serious changes may affect the mandibular growth in children following condylar fractures.

- Loss of anterior attachment of the tongue due to tissue loss causes an airway hazard that needs to be corrected primarily.

- Loss of bone in mental region or large areas:

- Difficulty in speech

- Difficulty in swallowing

- Drooling of saliva

- Un-aesthetic appearance

\subsubsection{Deformity in the Ascending Ramus of the Mandible}

No treatment is often required if the occlusion is satisfactory. Complete fusion of the bony segments to the temporomandibular joints may occur following the destruction of

the developing mandibular condyle after trauma or secondary infection. In this case, the destruction of the articular disc allows the contact between the bony fragments of ascending ramus and the glenoid fossa, finally resulting in ankylosis. When this occurs in children bilaterally, it shows reduction in lower third dimension resulting in appearance called "Bird Face deformity". This usually results in aesthetic and airway concerns, and psychological disturbances. Airway disturbances should be viewed with greater importance. Ankylosis in adults will result in occlusal abnormalities and difficulty in enunciation of speech and communication. Sometimes pseudo-ankyloses may also be observed.

\subsubsection{Surgical Options for Post-traumatic Residual Deformities}

Post-traumatic deformities include non-union, malunion/ malocclusion and facial asymmetry, and they may require secondary correction. These deformities can occur alone or in conjunction, sometimes as a sequel to a deformity.

\subsubsection{Non-union [45-50]}

They are fractures with arrested healing that requires further surgical treatment for correction. It is considered to be non-union when a fractured segment is mobile for 4 weeks without treatment or 8 weeks after surgical treatment.

\section{Causes for Non -union}

- Soft tissue infection

- Large fracture gaps

- Comminuted fractures

- Severe atrophic fractures

- Osteomyelitis

- Movements

Diagnostic considerations:

Clinical Examination:

- Identify persistent mandibular deformity.

- Tenderness at fracture site.

- Malunion in closed reduction techniques may be identified after release of maxillo-mandibular fixation.

Radiographic Findings:

Irregular radiolucency with mottled fracture ends.

Management:

- Extra-oral approach is the best option as it allows good visualisation. Transoral approaches may be considered in indicated cases.

- It is followed by the debridement for removal of any fibrous tissue, necrotic bone or failed hardware.

- Following this, adequate occlusion and maxillomandibular fixation is achieved. The fracture is reduced, 
and then reconstruction plates are fixed with the help of screws away from the fracture.

- Considering less mineral (even though appearing normal) content in the site near the fracture, it is recommended to place screws no closer than $7-10 \mathrm{~mm}$.

- Autogenous bone grafting may be used to re-establish continuity of mandible in areas where the bone contact is inadequate.

- In younger patients and well-vascularised areas, union of small gaps is successful.

\subsubsection{Malunion/Malocclusion: $[46,51,52]$}

It can occur in any type of mandibular fracture when segments heal in improper alignment. Malunion is often due to inadequately established occlusion, inadequate anatomic reduction and poor adaptation of fixation plate.

Figs. 61.3, 61.4, 61.5, and 61.6 depicts malocclusion related management of deformities.

Diagnostic Considerations:

It is often diagnosed with malocclusion and more associated with rigid internal fixation. Dental models are used to study and plan the occlusion.

Management Considerations:

- Revisit of the surgical site may be necessary to correct the errors due to rigidity.

- Minor occlusal corrections can be done with orthodontic treatment.
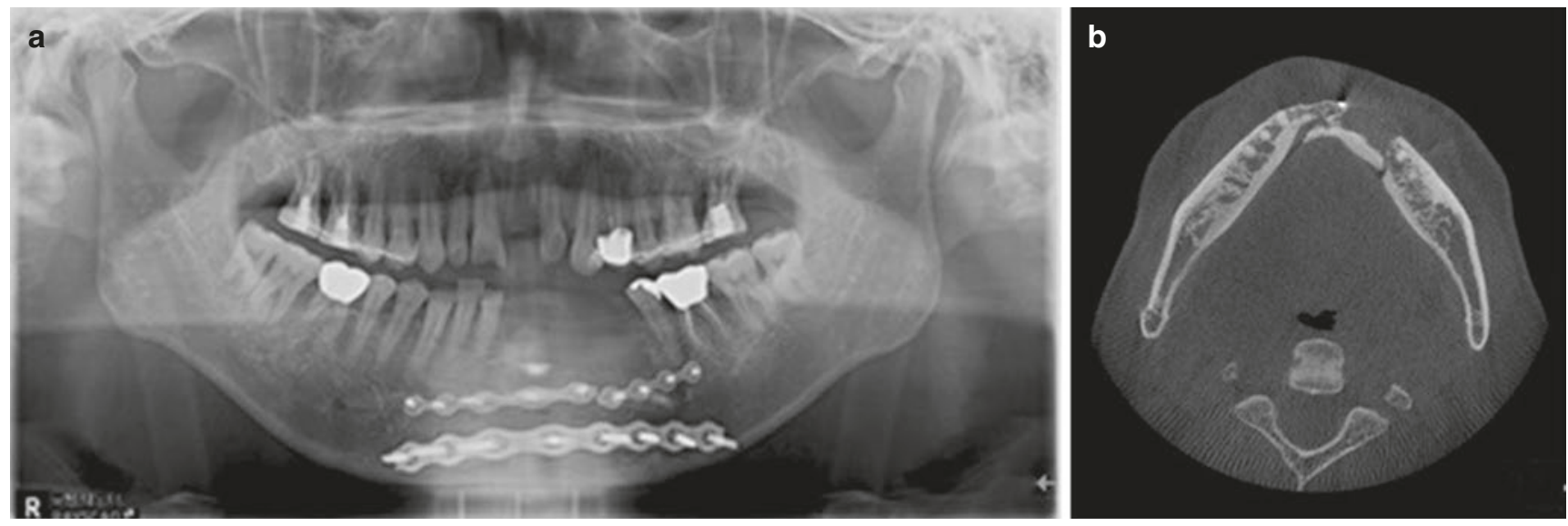

Fig. 61.3 Malocclusion following trauma surgery with multiple loss of teeth in mandible and associated osteonecrosis. Patient managed with iliac grafting of mandibular osteonecrosis site, followed by implant rehabilitation and vestibuloplasty. Preoperative radiograph. (a) Panoramic radiograph (b) Cone beam computed tomography scan.
(Reference for Figs. 61.3, 61.4, 61.5, and 61.6) (http://creativecommons.org/licenses/by/4.0/), Kim SY, Choi YH, Kim YK. Maxillofac Plast Reconstr Surg. 2018;40(1):27. Published 2018 Oct 15. doi:10.1186/s40902-018-0167-z (springer open)
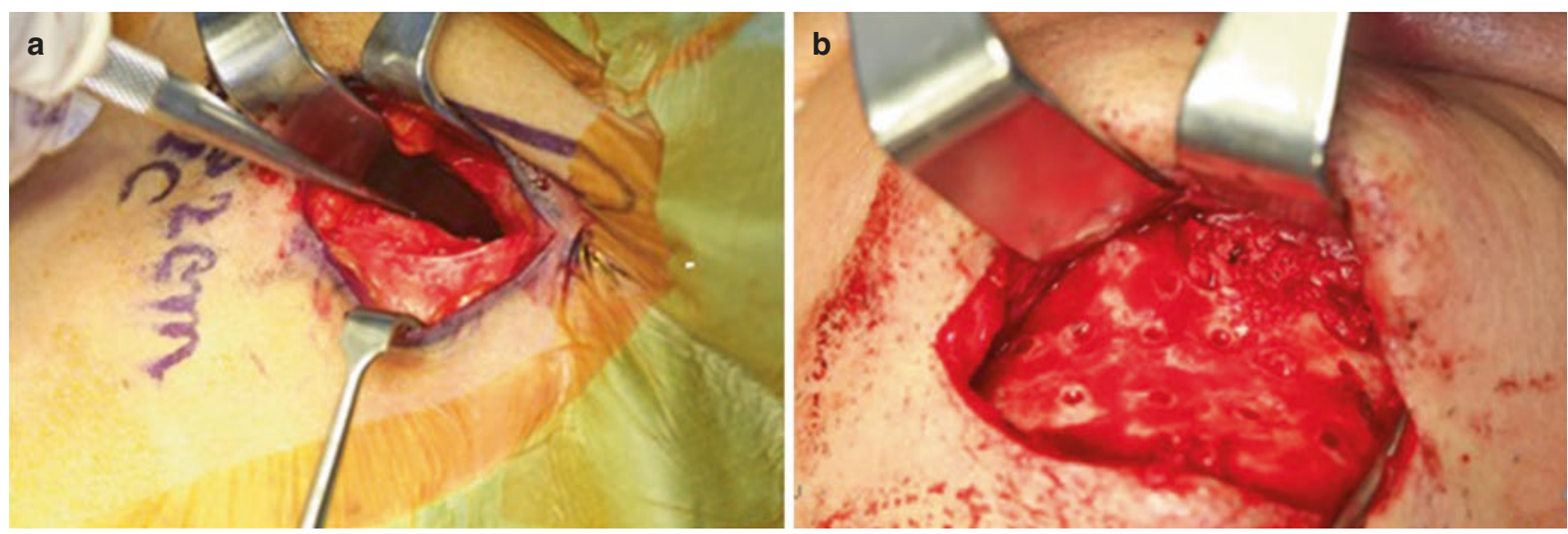

Fig. 61.4 Clinical intra-oral photograph showing. (a) Iliac bone harvesting. (b) Grafting of the harvest iliac bone into the mandible defect 


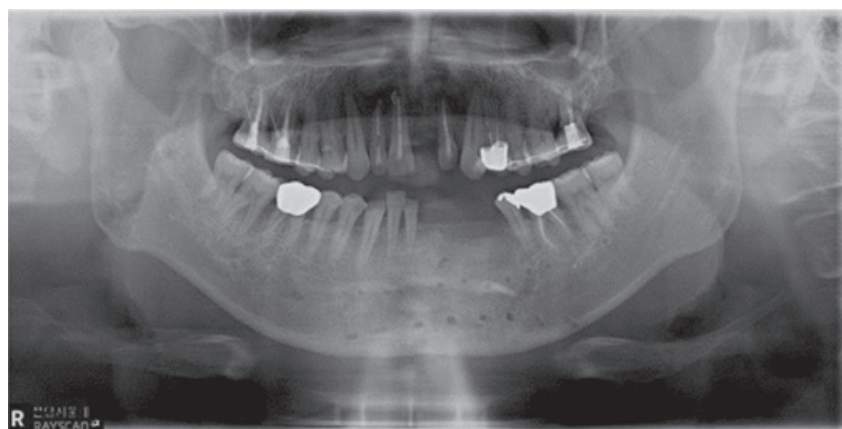

Fig. 61.5 Post-operative OPG

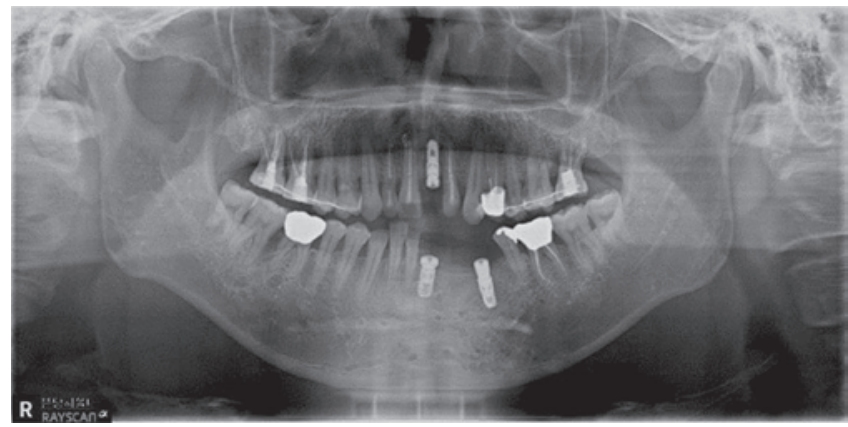

Fig. 61.6 Post-operative OPG after implant placement for dental rehabilitation

\subsubsection{Early Malunions}

- Surgical approach is similar to the primary treatment.

- Old hardware is removed $\rightarrow$ adequate occlusion achieved $\rightarrow$ with maxillo-mandibular fixation $\rightarrow$ fracture reduction if necessary $\rightarrow$ new fixation is done $\rightarrow$ new occlusion is verified with release of the fixation.

\subsubsection{Late Malunions}

- Surgical approach is determined based on type of osteotomy.

- Study models are used to study the occlusion and plan a mock surgery.

- Management includes osteotomies for proper establishment of anatomy and occlusion.

- Mandible is re-fractured $\rightarrow$ occlusion is achieved with the help of a surgical splint $\rightarrow$ maxillo-mandibular fixation is obtained $\rightarrow$ new rigid fixation $\rightarrow$ occlusion is verified after the release of maxillo-mandibular fixation.

- Bone grafts may be used to close gaps whenever necessary.

\subsubsection{Malunions/Malocclusion and Condylar Fractures [53-56]}

- Majority of condylar fractures when treated "closed" may develop malunion. However, condylar malunion may not always cause malocclusion.
- Quality of the functional rehabilitation of the mandible is an more important factor than the type of treatment (closed or open).

Diagnostic Considerations:

- Radiographs and malocclusion are key in examination.

- No treatment or previous unsuccessful treatment is a main reason for malocclusion following condylar fractures.

- Degree of mandibular ramus deformity is essential to determine the necessity for a re-surgery to correct malocclusion following condylar fracture.

Treatment Considerations:

- Unilateral or bilateral fractures.

- Time period between fracture and treatment of malocclusion.

- Availability of remaining stable dentition.

Management Considerations:

- Minor occlusal discrepancies may be treated with orthodontics, prosthetic rehabilitation, reconstruction and occlusal adjustments if indicated.

- TMJ reconstruction may be indicated-when the remaining ramus is short with multiple fragments and large movements are required to correct occlusion.

- Orthognathic surgery may be indicated in long-standing malocclusions.

- Functional therapy can be done up to 3 months for management of malocclusion.

\subsubsection{Facial Asymmetry [46]}

- Usually as a sequel to malunion, non-union and inadequate fixation.

- A number of clinical scenarios may present itself to facial asymmetry

Diagnostic Considerations:

- Early stages: Difficult to diagnose because of the swelling.

- Antero-posterior cephalometry or CT scans are confirmatory.

- Facial, dental and radiographic analyses are done.

Management Considerations:

- Treatment similar to malunions and malocclusions.

- In cases where the defect is diagnosed early, the mandible can be approached through the initial surgical wound, the hardware may be removed, mal union corrected and new fixation can be placed.

- Orthognathic surgeries in cases of established facial asymmetries. Surgical splints and model surgeries help in 
surgical planning. Asymmetry is corrected, and new occlusion is verified with new fixation. The procedure similar to principle treatment. Additional osteotomy may be required depending on the type of original injury.

\subsubsection{Principles of Mandibular Reconstruction $[45,57]$}

Reconstruction of larger defects of the mandible is discussed in Chap. 88.

Marx and Saunders listed the goals of mandibular reconstruction in order to consider a grafting procedure successful.

- Restoration of continuity is the key since the mandible is a bone with two articulating ends supported by muscles with opposing forces. Deviated mandibular segments need to be realigned not only to improve facial aesthetics but also to restore essential function movements.

- Restoration of alveolar bone is another essential aspect to aid in the functional rehabilitation of the patient. The process of mastication and the efficiency to masticate are possible only once the necessary alveolar bone height has been obtained. In patients with osseous defects, this helps in the placement of a prosthesis.

- Restoration of osseous bulk is vital to provide the required amount of osseous tissue to withstand forces and perform normal function. Fracture of the graft area may occur when the area is too thin, lacking the bulk to withstand functional forces directed towards the bone.

\subsubsection{Midface Deformities [3, 58]}

The midface is a critical zone of the maxillofacial region concerning both aesthetics and function. Midface includes structures like the maxilla, palate, orbit, cheek, upper lips, eyelid and nose. It is often an area that poses a significant challenge to a maxillofacial surgeon for reconstruction. Orbit is usually challenging to reconstruct in secondary setting mainly due to chances of scarring. Due to the difficulty in obtaining good results in primary surgery, the nose and auricle are best considered for correction in a secondary setting. Figure 61.7 shows areas of the midface.

Objectives in Correcting Midface Deformities [58]

- Restoration of midface projection

- Restoration of occlusion

- Providing support for the orbit

- Filling the volume of the orbit

- Restoration of palate competence

- Restoration of functional harmony

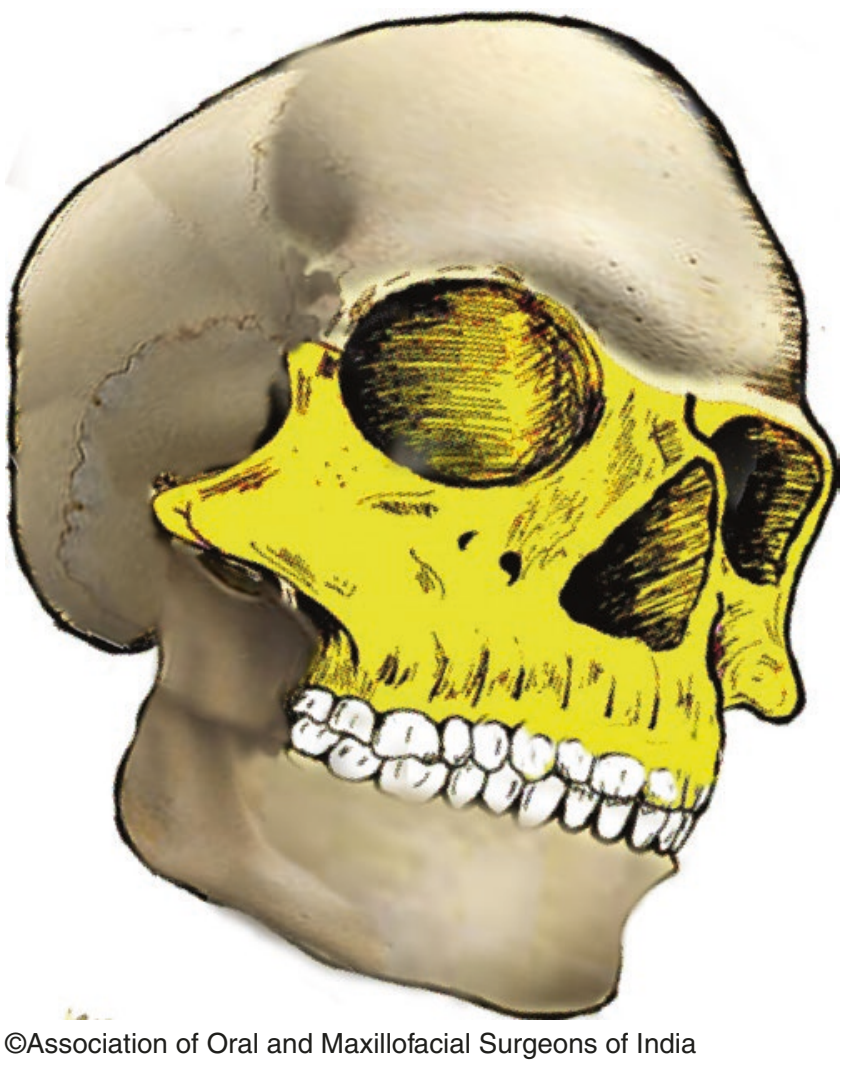

Fig. 61.7 Highlighted (yellow) areas represent midface region

Along with the reconstruction of the hard tissue, it is important to correct associated soft tissue defects as well. Failure to correct the primary deformities may result in sequelae of defects of the associated soft tissues and end up in affecting the functional quality of life of the patients.

Indications to Correct Midface Defects [58]

- Untreated/avoided defects during primary reconstruction

- Poor result following primary reconstruction (partial or complete loss of flap, non-union of bone, oro-cutaneous fistula)

- Poor outcome in primary reconstruction due to poor planning

- Post-operative complications that may lead to hematoma and scarring

Diagnostic Workup: [58]

Treatment planning for midface changes requires careful planning and knowledge of previous treatments to achieve the best result.

- Evaluate general status of the patient (age, history of tobacco, alcohol abuse, nutritional status, and presence of co-morbidity) 
- Accurate assessment of anatomic defects

- Assessment of quality of tissue involved, surrounding tissues and status of scar

- Availability of healthy surrounding tissue

During the workup, it is necessary to eliminate cases of unresectable conditions like distant metastasis or recurrence in oncology or non-traumatic cases.

Diagnostic Assessment: [58]

Assessment requires evaluation of surface or volume of missing tissues. Assessment should include evaluating defects in the bone, skin, musculature, innervation and mucosa (Chart 61.4).

Treatment Options: $[3,58]$

Surgical correction in this region varies from prosthetic replacement to complex microvascular reconstructive surgeries.

\section{Surgical Options:}

- Local or regional flaps for small to moderate defects.

- Secondary free flaps: iliac crest flaps, fibula flaps, subscapular free flaps.

- Microvascular surgeries are primarily done in major defects.

- Microvascular flaps provide adequate and necessary amount of well-vascularised bone and/or soft tissue augmentation, thereby enabling a better 3D fitting flap and closure.

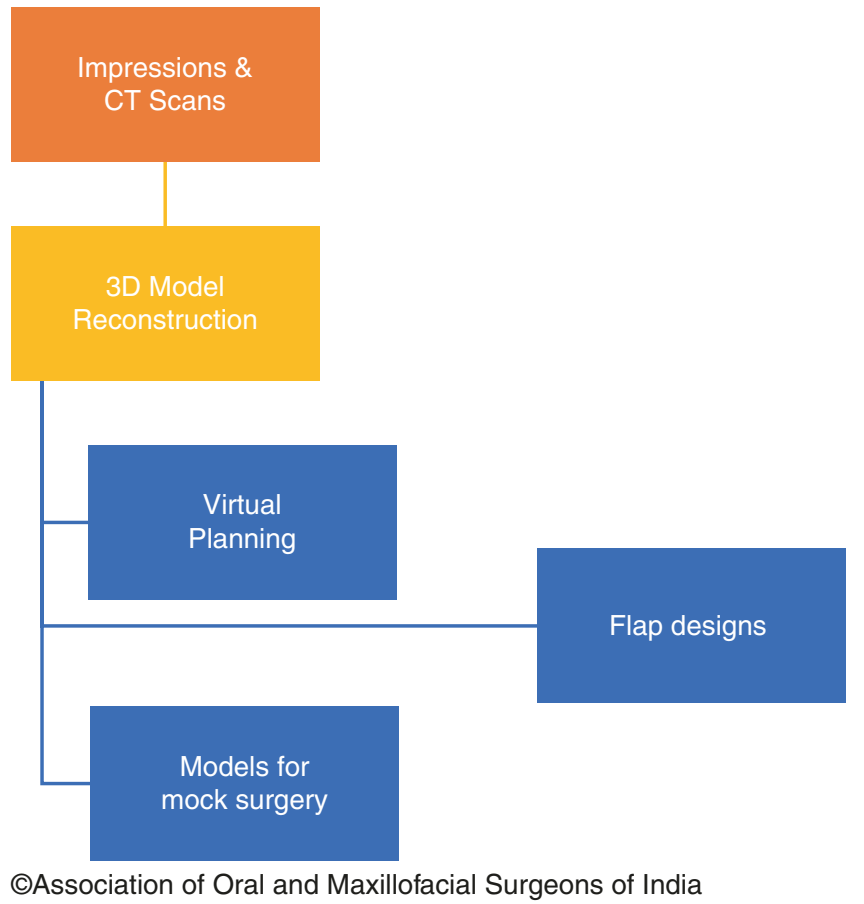

Chart 61.4 Diagnostic assessment
- Critical evaluation is to be done in previously irradiated or operated midfacial defects.

Current methods under development include tissue engineering for ideal regeneration of the tissues in head and neck defects. Facial transplantation has also paved newer paths in this field, but indications are restricted.

Other Non-surgical Options: [58]

Maxillofacial prosthesis:

- Palatal obturators in maxillectomy cases.

- Complex defects affecting structures like the nose, orbit and those which cannot be restored with flap reconstruction may be managed by maxillofacial prosthesis. Recent advancements include supporting the prosthesis with dental implants.

\section{Ancillary Procedures: [3, 58-61]}

- Additional supportive techniques may help to improve the outcome of a correction in midface re-operative procedures.

- CT images are useful in designing adequate fronto-orbital facial contours.

- Free bone grafts for facial contouring are indicated for upper midface defects. The bone grafts can be obtained from calvaria and synthetic implants-porous polyethylene, methyl methacrylate and titanium mesh. However, it is contraindicated in a previously irradiated area and in cases of oral cavity communication.

- Combination of titanium mesh and soft tissue may be helpful to provide support for the globe.

- Liposuction is an excellent alternative technique to fill certain residual defects following midface reconstruction. Microvascular flaps may help fill residual flattened areas.

- Distraction osteogenesis: Mainly indicated in mandibular repair, it is also used in the repair of minor maxillary bone defects which cannot be treated with bone flap reconstruction (refer Chap. 87).

Oral Rehabilitation:

- Implant-supported prosthesis with good osseointegration is often considered as the best option in oral rehabilitation. Peri-implant hygiene and osteointegration are important for the success of dental/zygomatic implants in oral rehabilitation procedures.

- Dental implants are most helpful for oral rehabilitation. Implants may be placed during the primary reconstructive procedure or preferably as a secondary procedure.

- Zygomatic implants may also be used when regular alveolar bone reconstruction is not possible.

- Implant placement in previously irradiated areas may not give the best results, and hence it is a contraindication. 


\subsubsection{Residual Maxillary Deformities [3, 58]}

Goals in Correction of Maxillary Deformities

- Restoration of function

- Restoration of occlusion

- Restoration of original relationship between thirds of the face

Common Maxillary Deformities May Be Due to:

- Malpositioned maxillary fractures

- Undiagnosed fractures - untreated dislocated fractures

- Severely comminuted fractures with associated damages

- Untreated old fractures

- Edentulous displaced maxilla

- Post-traumatic hypertelorism

Essentials for Treatment Planning:

- Preoperative photographs (full face, profiles pictures, frontal and lateral views of occlusion, palate, floor of the mouth and other required projections).

- Detailed clinical assessment and treatment of other existing carious and inflammatory conditions of the oral cavity.

- Models and radiographs-OPG, lateral cephalometric X-rays

- Current imaging and planning techniques: CBCT helps in $3 D$ virtual planning to design flaps and to create $3 \mathrm{D}$ models for planning and mock surgery (61.5).

\subsubsection{Immediate Repositioning of Maxilla and Midface Complex}

Open Surgical Immediate Mobilisation Treatment: This is indicated in conditions where total mobilisation is not possible. These are cases that are treated after 6 weeks or more after trauma, or even years later, usually cases where partial or complete consolidation has already taken place. The principle of surgical treatment is often the same as in the treatment of primary maxillary and midface treatments.

Old Fracture Segments: Old fracture segments in the anterior maxilla can be corrected by techniques described by Wassmund (1935) and Wunderer (1962) in cases of protruded maxilla. It is key to observe any scars in the labial vestibule as that may affect the vasculature to the alveolar process. Wassmund's method should be preferred when a scar is present; otherwise, Wunderer's method may be followed in which maintenance of labial blood supply is essential. In contrast, Schuchardt K suggested a single-stage technique which involved an osteotomy of the lateral alveolar process and relocation to its original alveolar location [62-64].

\subsubsection{Old Le Fort I and II Fractures [3]}

Untreated Le Fort I Fractures: An incision may be made at a point horizontally through lateral and anterior maxillary sinus walls. Osteotomy is done to ensure that the plates are placed on both sides of the stable bone region. Line of osteotomy does not precisely follow the line of fracture.

Old Le Fort II Fractures [3]: If there's no cosmetic significance or less damage to the nasal region-similar procedure may be followed. Le Fort II osteotomy is indicated when the nose has sunken, and the midface is shortened.

In the above scenarios, Le Fort I and II osteotomies may be done when either occlusion needs to be restored or there is an aesthetic concern. Bone grafts may be used in the region of the bridge of the nose below the buttress and also between pterygoids and the maxillary tuberosity if possible (Figs. 61.8 and 61.9).

\subsubsection{Displaced Edentulous Maxilla [3]}

- Minor displacements may be corrected with osteotomies, only if the disturbance along the intermaxillary relationship in the sagittal plane is minimal. Otherwise, it is justifiable to treat with a prosthesis.

- In case of severe displacements of maxilla which results in the appearance of a skeletal Class III, the maxilla has to be surgically replaced to its original place with the help of bone grafts.

\subsubsection{Old Le Fort III Fractures (Figs. 61.10 and 61.11)}

Le Fort III osteotomy is indicated in old Le Fort III fractures when the deformities may be seen in the entire midface region with dislocations in orbital margins and zygoma. Unilateral osteotomy may be indicated when only one side of the face is affected. Occasionally in cases of comminuted fractures of the midface, a Le Fort I osteotomy may be needed to be done along with Le Fort III osteotomy procedure. This is essential to correct the occlusion in untreated midface fractures. It may be challenging to carry out a re-treatment for comminuted midface fractures. Segments may be stabilised separately considering the complex nature of the fracture. The procedure can be simplified by first mobilising the entire midface complex with Le Fort III osteotomy and then followed by Le Fort I osteotomy (Figs. 61.12, 61.13, 61.14, 61.15, and 61.16 shows surgical management of a mid face deformity by onlay grafting; All images 61.12-61.16 are from the same patient) (Figs. 61.17, 61.18, and 61.19 shows clinical images of management of post operative malocclusion; all images 61.17-61.19 are from the same patient). 


\section{Historical perspectives of therapeutic options for maxilla and midface correction ${ }^{3}$}

Maxillary mobilisation can classified into gradual and immediate repositioning. Gradual repositioning of maxilla \& midface complex were opted in cases where cicatricial fixation had already taken place. Gradual repositioning of midface/maxilla fractures using elastic traction, headframe, roll extension method, orthopaedic apparatus are mentioned here with respect to the historical perspective of therapeutic options. However, those methods are not current in usage.

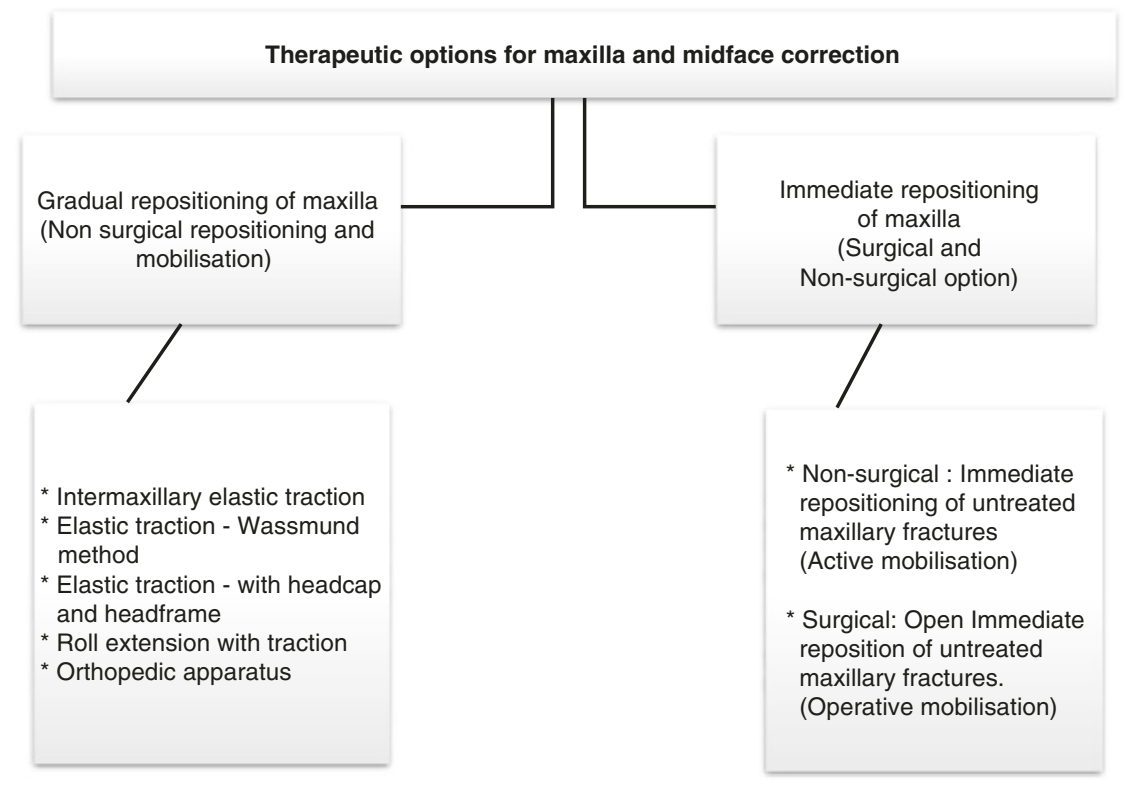

CAssociation of Oral and Maxillofacial Surgeons of India

Chart 61.5 Historical perspectives of therapeutic options for maxilla and midface correction [3]

Fig. 61.8 Schematic diagram showing preoperative old untreated midface fractures
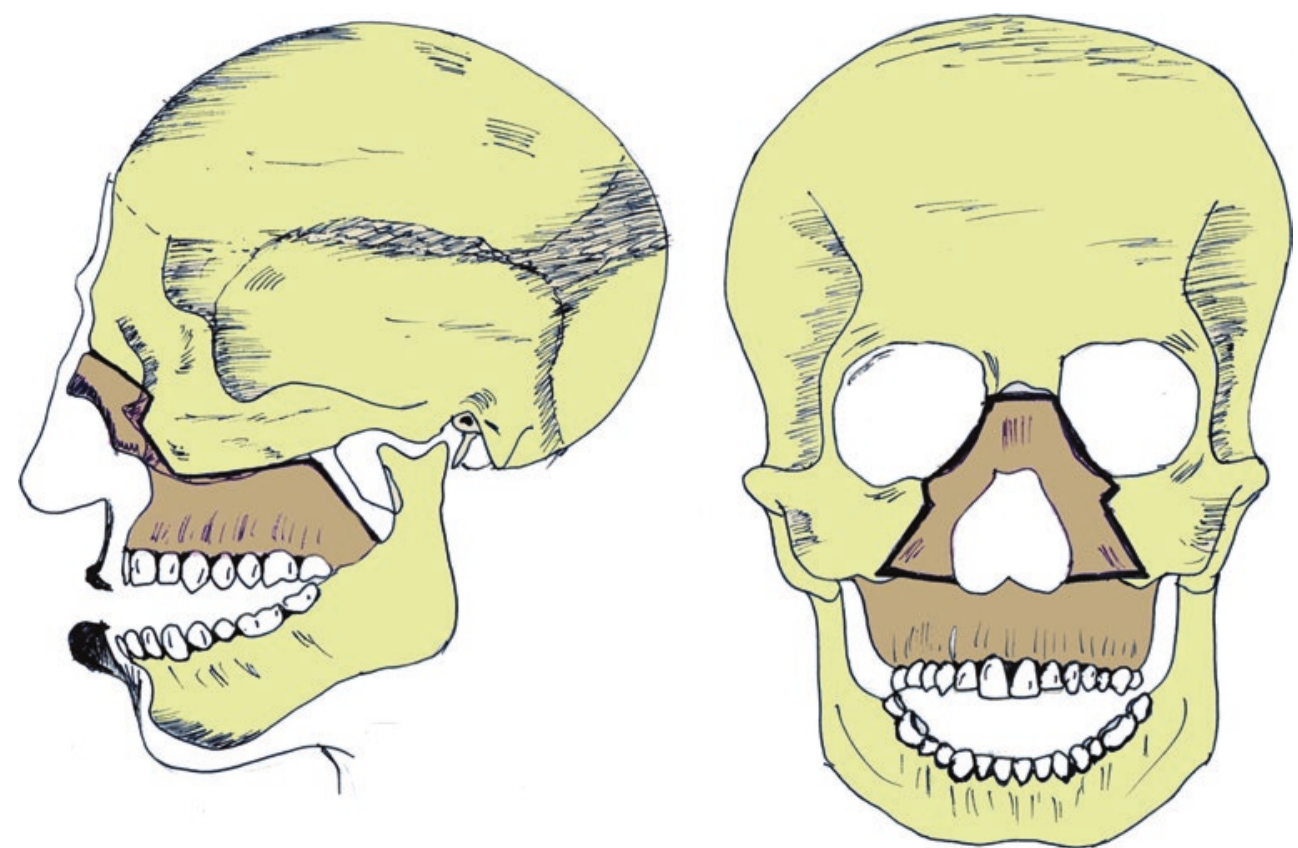

(CAssociation of Oral and Maxillofacial Surgeons of India

\subsubsection{Post-traumatic Hypertelorism} $[3,44,65-71]$

It is a complication that may arise in fractures of midface complex when there is a dislocation of one or both orbits.
Treatment is similar to congenital hypertelorism, and procedure may follow as suggested by Tessier et al. (1967). Stereolithographic models are best used for treatment planning. Although Tessier developed the extra and intracranial approach to correct the deformity, it was further refined later by Tessier, Converse, Van der Meulen et al., Monasterio 
Fig. 61.9 Schematic diagram showing post-operative scenario following combined Le Fort 1 and Le fort II. Defects as a result of repositioning shaded as brown are areas to be filled with bone graft
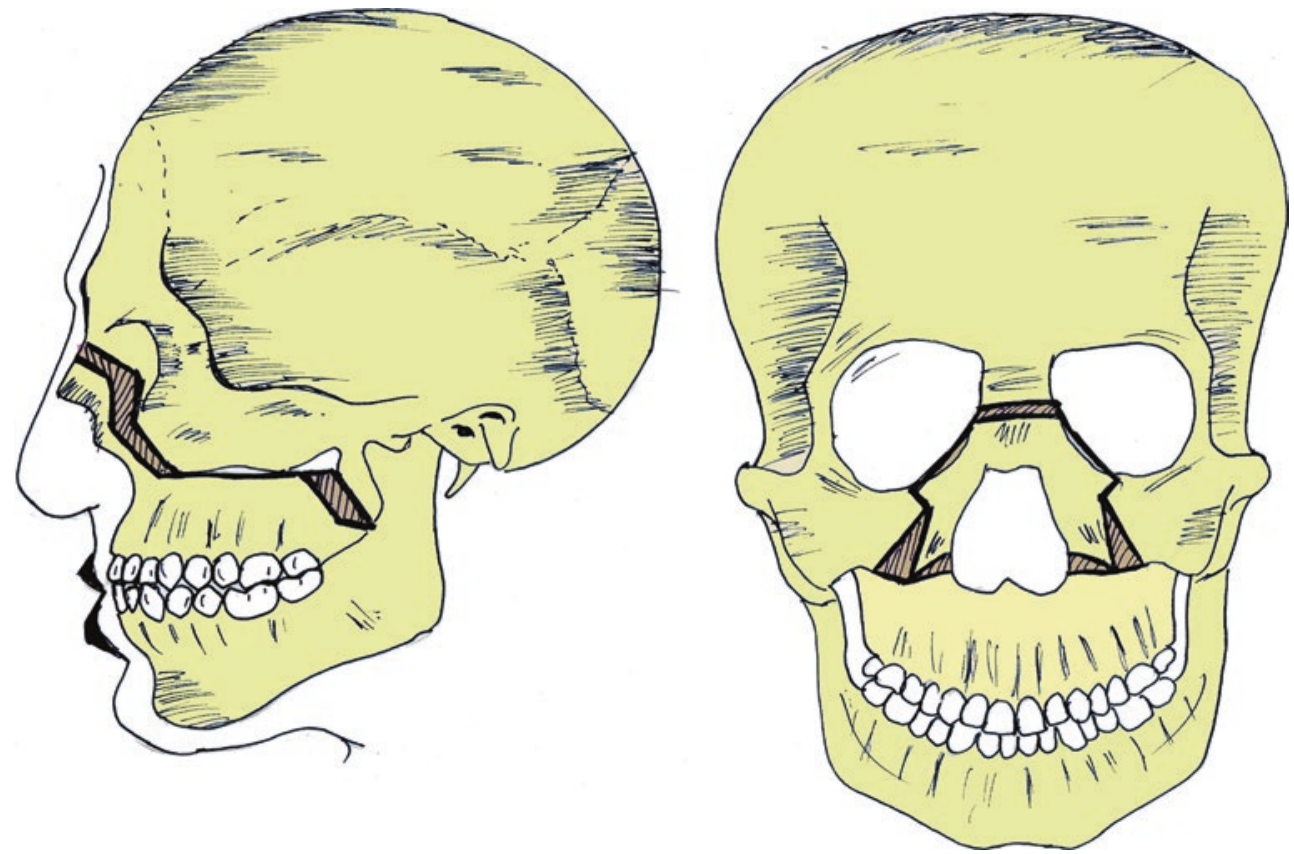

CAssociation of Oral and Maxillofacial Surgeons of India et al. and Marchac et al. They were able to visualise the bony orbit in two parts with the outer square box containing the globe and the inner cone housing the optic nerve. It was established that if these two parts could be separated, the outer box can be moved without affecting the vision.

Goals of surgery for hypertelorism include:

- Correction of orbital dystopia

- Bringing the orbits closer together

- Creation of normal nose with adequate projection

- Narrowing of the nasal dorsum

- Correction of associated soft tissue defects over the nose, nasal clefts or even displaced eyebrows

\subsubsection{Residual Zygomatic Deformities [3, 58]}

Periorbital area is often a zone of interest in the midface region from a functional and aesthetic point of view. An imbalance in this region could result in aesthetic concern and altered vision. This can be due to malunion of the fracture of the zygomatic complex. Any untreated fracture for longer than 10 weeks is considered to be an old fracture and results in malunion-a stage at which a procedure needs to be done to correct any deformity.

\section{Clinical Signs and Symptoms}

1. Facial asymmetry

2. Facial disharmony

3. Dislocated eyeball

4. Diplopia

5. Paraesthesia — infraorbital nerve

6. Limited movements of the mandible

Soft tissue damage like a torn lateral canthal ligament, malpositioned zygomatic bone, zygomatic arch or fragments of the orbital arm may result in an asymmetry of the lateral midface. Corrective surgeries may be required in case of a destroyed orbital bone as well. More often, patients visit the surgeon for aesthetic reasons. It may be often difficult to correct aesthetics when it involves post-traumatic deformities in the malar prominences (Table 61.3).

\subsubsection{Associated Defects of the Orbital Zone [3]}

- Dislocated eyeball: Usually occurs as a sequel to zygomatic fractures, and slight dislocation may be seen after primary treatment. Displaced orbital floor due to enlargement of the socket or the loss of the orbital content due to 

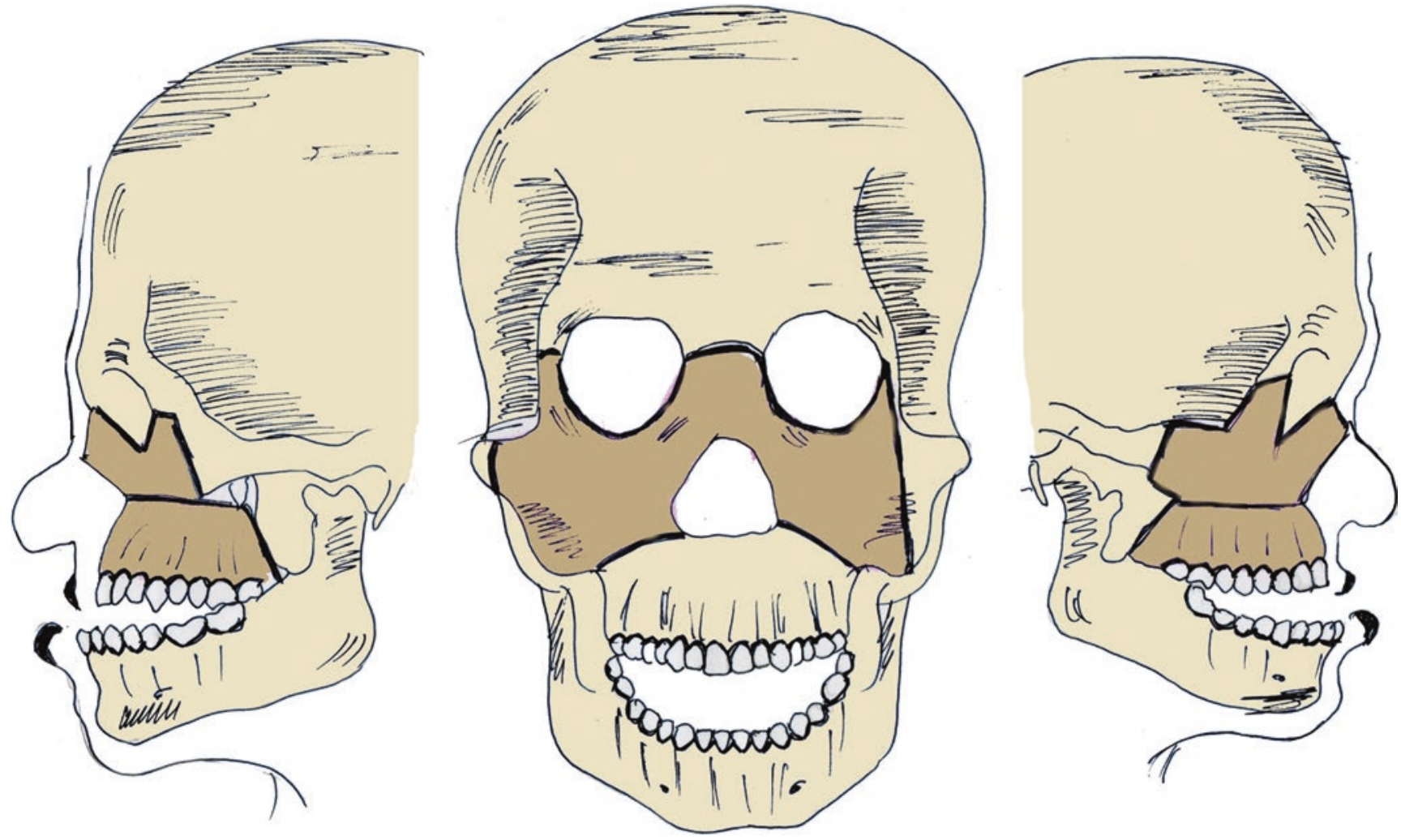

(C)Association of Oral and Maxillofacial Surgeons of India

Fig. 61.10 Schematic diagram showing old untreated Le fort III fractures
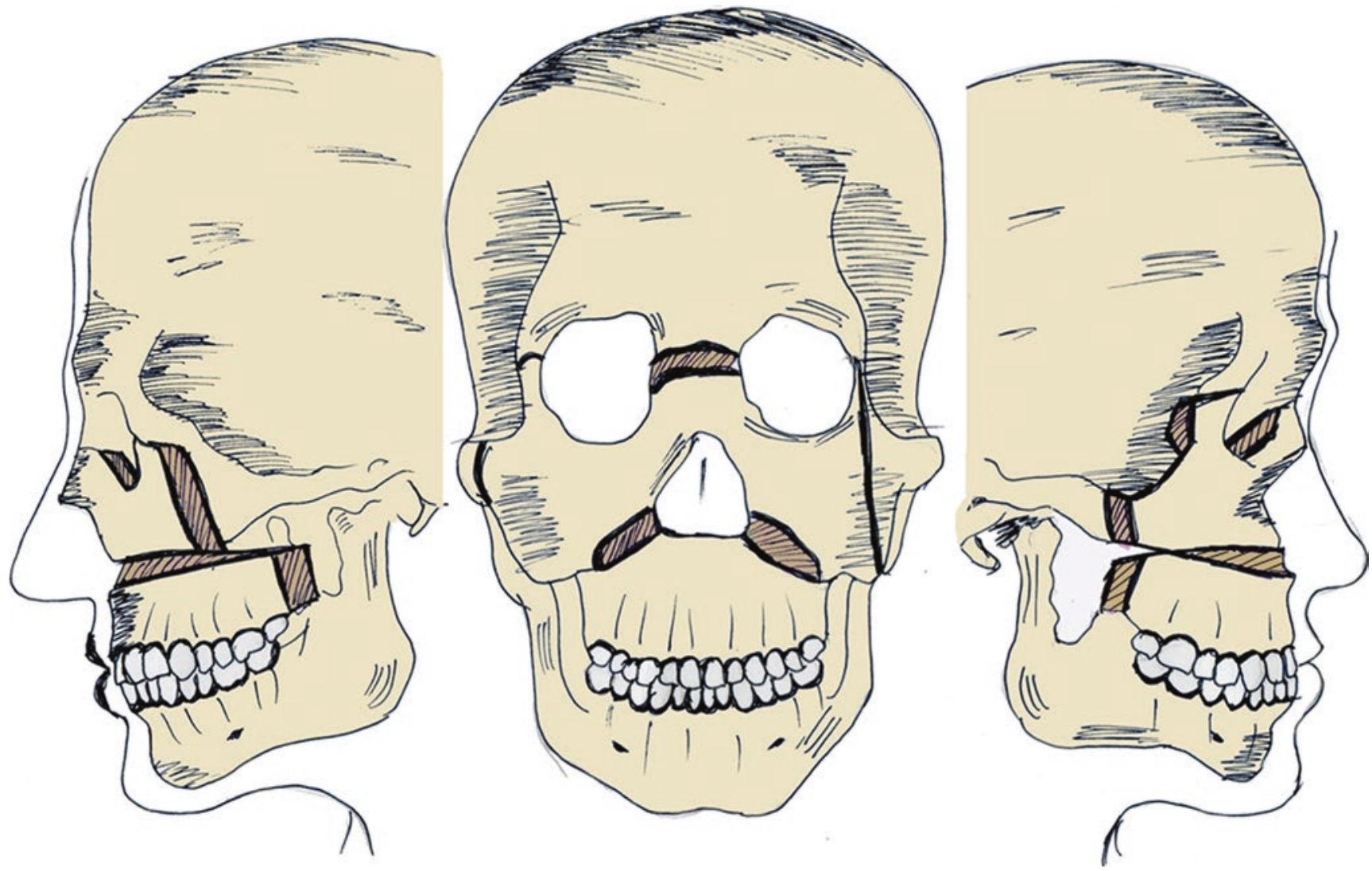

(C)Association of Oral and Maxillofacial Surgeons of India

Fig. 61.11 Schematic diagram showing post-operative following combined Le Fort I and Le fort III. Defects as a result of repositioning shaded as brown are area to be filled with bone graft 

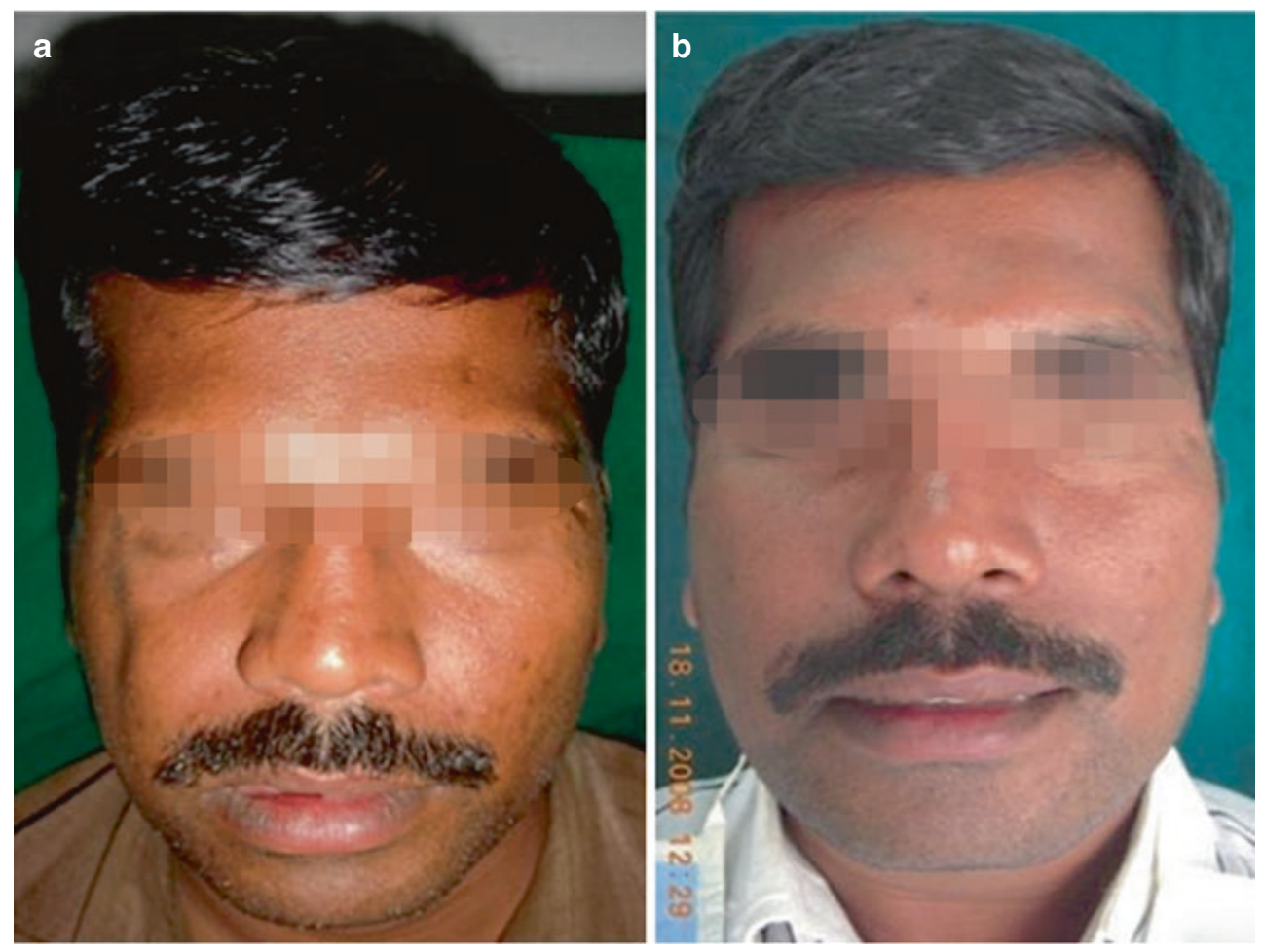

Fig. 61.12 Midface deformities showing residual deformities. (a) preoperative extra-oral photograph showing facial asymmetry, depressed malar prominence (right side), and incompetent lips. (b) Post-operative extra-oral photograph. (Reference for Figs. 61.12, 61.13, 61.14, 61.15, and 61.16: Ranganath K, Hemanth Kumar HR. The correction of posttraumatic pan facial residual deformity. J Maxillofac Oral Surg. 2011;10(1):20-24. https://doi.org/10.1007/s12663-010-0088-6) springer publishers
Fig. 61.13 (a) Preoperative intra-oral photograph showed deranged occlusion with right anterolateral open bite. (b) Post-operative intra-oral photograph
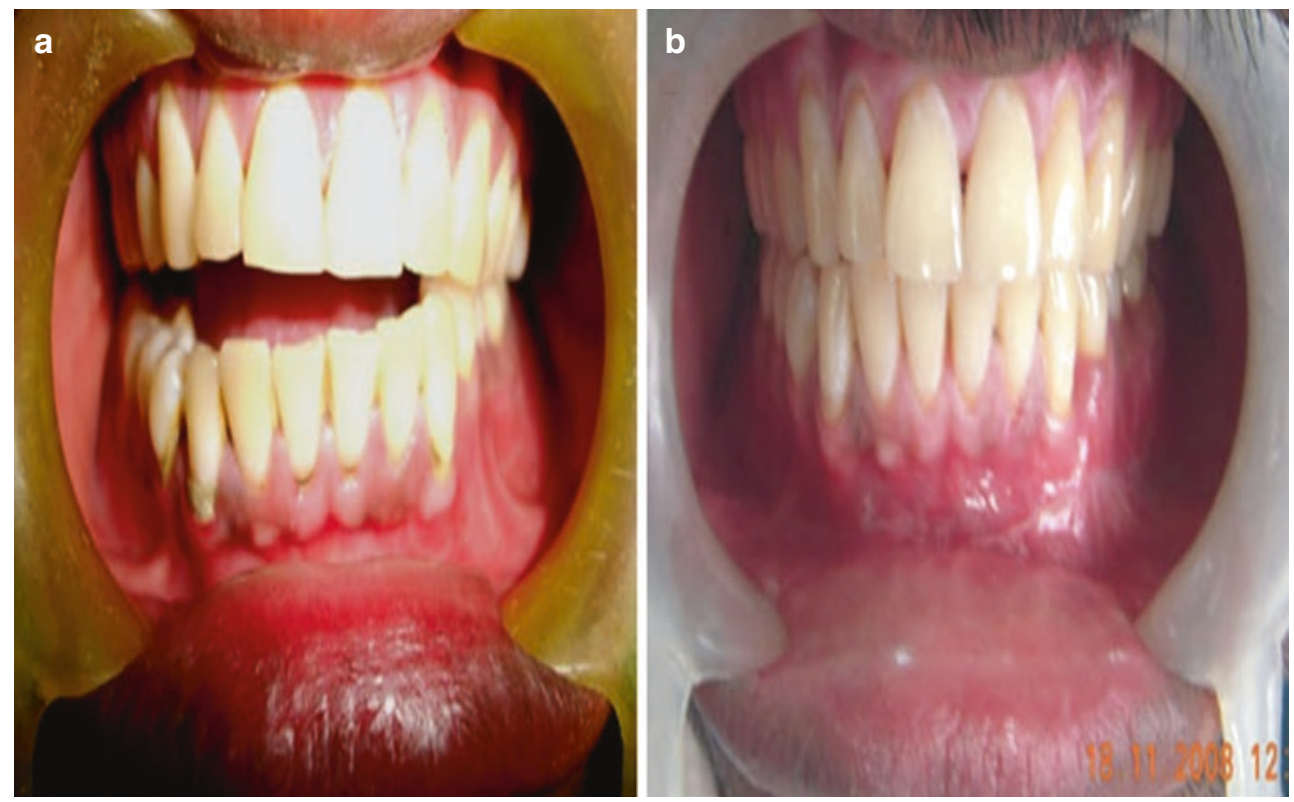

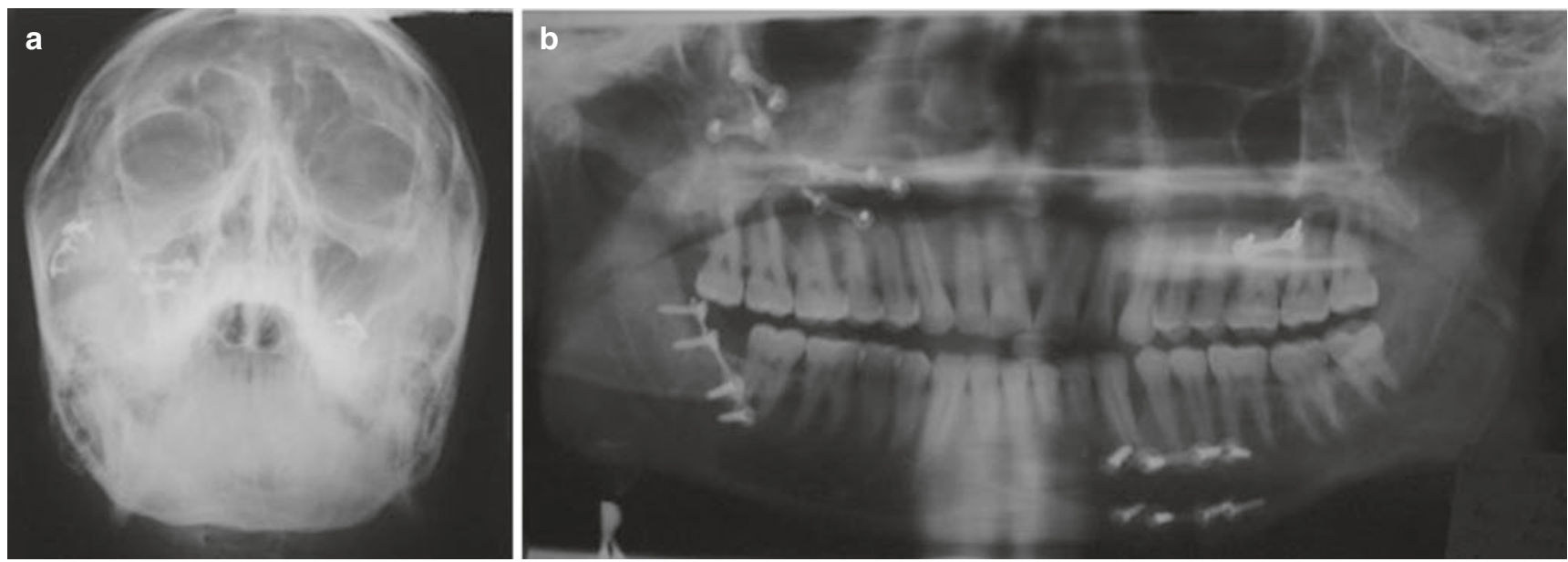

Fig. 61.14 (a) Post-operative PNS radiograph. (b) Post-operative orthopantomograph
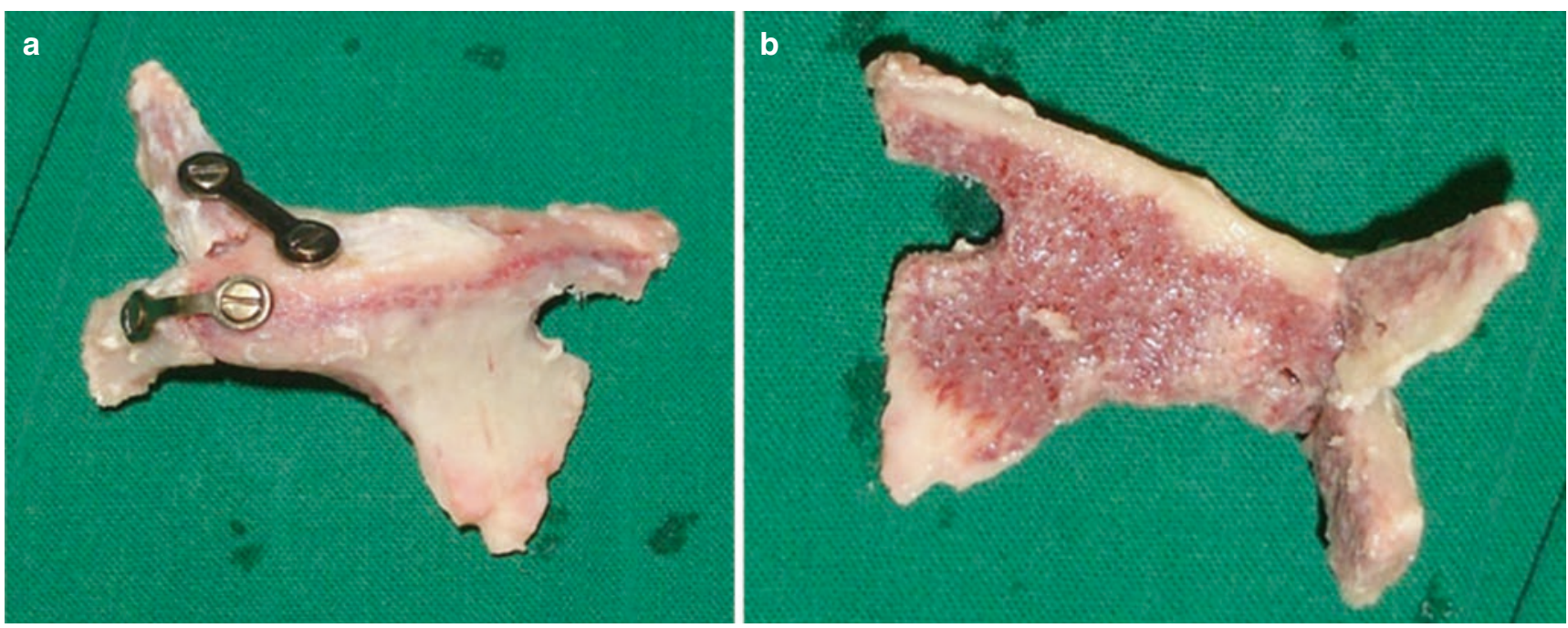

Fig.61.15 (a, b) Sculptured iliac bone onlay graft
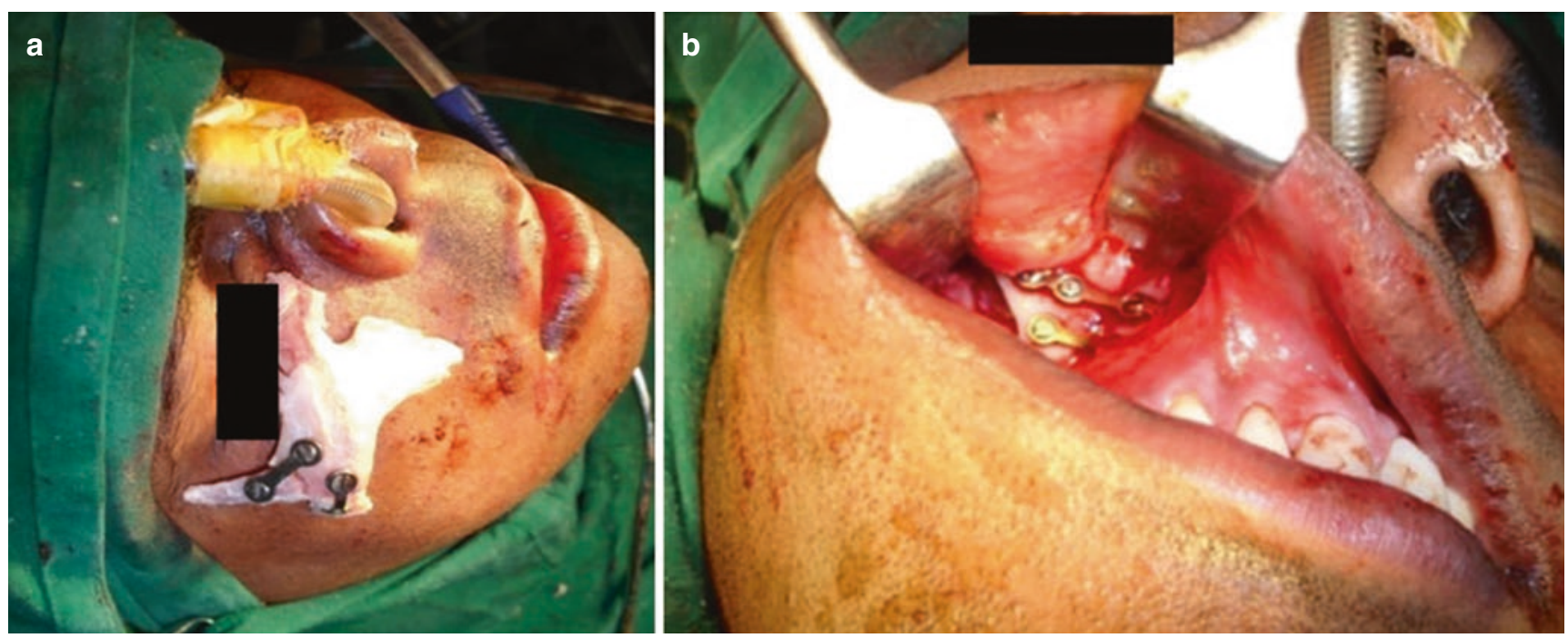

Fig. 61.16 (a) Onlay graft positioned on the patient. (b) Onlay graft plated to the maxilla 


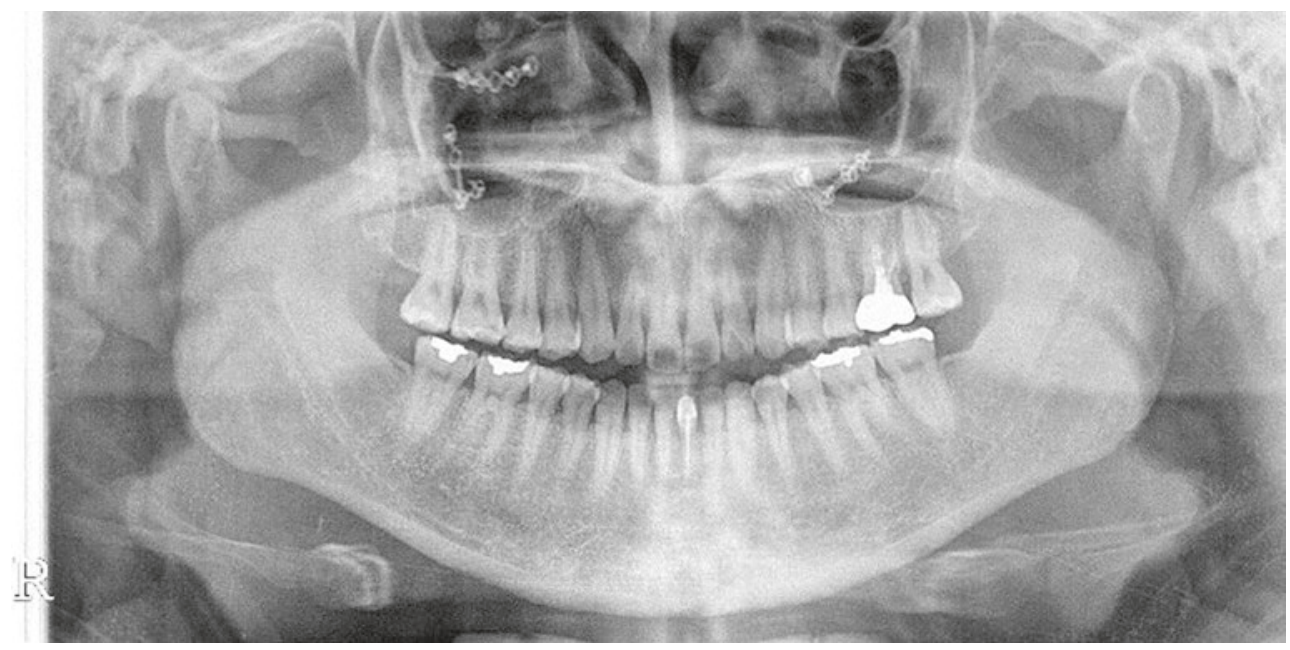

Fig. 61.17 Patient complains of open bite, malocclusion, deviation of maxilla and TMJ tenderness after trauma surgery. Preoperative OPG showing malunion in maxilla and malocclusion. (Reference for Figs. 61.17, 61.18, and 61.19: Kim, Sang-Yun et al. "Post-operative mal- occlusion after maxillofacial fracture management: a retrospective case study." Maxillofacial plastic and reconstructive surgery vol. 40,1 27. 15 Oct. 2018, https://doi.org/10.1186/s40902-018-0167-z. (http://creativecommons.org/licenses/by/4.0/), springer open
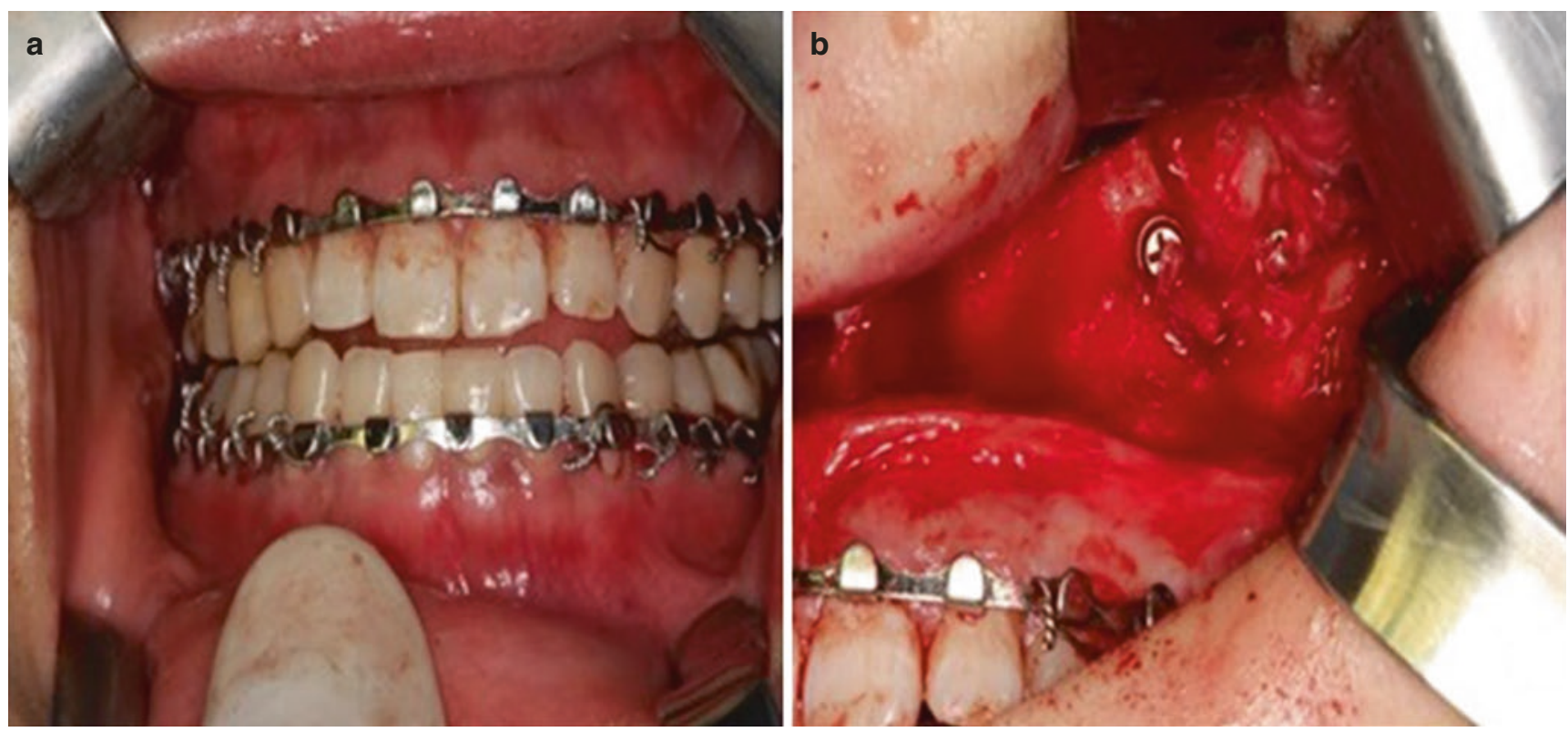

Fig. 61.18 Photograph during the operation. (a) Shows severe malocclusion before second operation. Arch bar placed for intermaxillary fixation. (b) Fracture site exposed, malunion segments detected
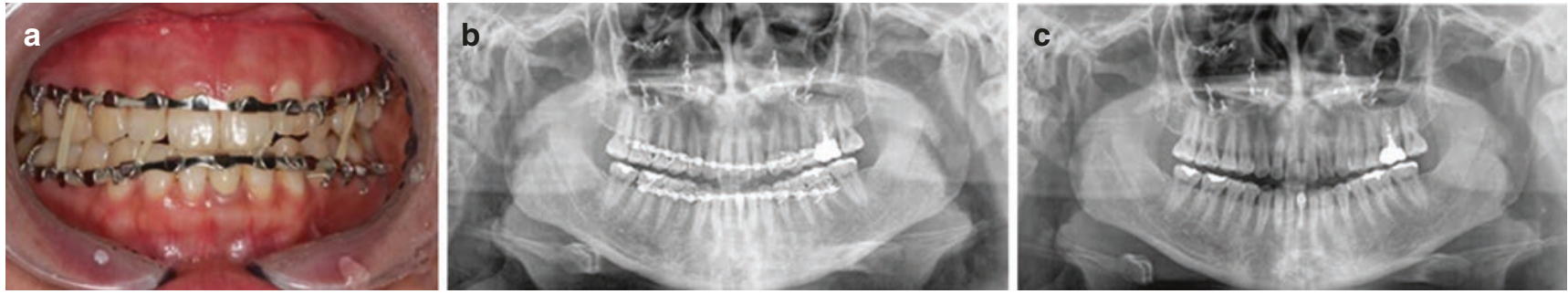

Fig.61.19 Le fort I osteotomy done under general anaesthesia to resolve malunion and malocclusion. TMJ pain resolved following the treatment. (a) Post-operative (1 month) photograph showing resolution of malocclusion. (b) OPG after 1 month. (c) OPG 1 year after operation 
soft tissue displacement or necrosis may result in enophthalmos and/or downward displacement of the globe.

- Diplopia: Usually due to severe dislocation of the eyeball, but severe diplopia may more likely occur as a consequence to trauma to the cranial nerves, scarring of the extraocular muscles or prolapse and entrapment of orbital soft tissue. Waiting period before re-treatment of diplopia neural and muscle damage is at least 12 months and 15 months, respectively, to observe if the diplopia subsides. Diplopia is differentiated into heterotropia and heterophoria. While sometimes heterophoria may not even need a correction, in certain cases of severe heterotropia, the patient is advised to maintain a titled head position to avoid any double vision. Sometimes double vision may persist even after the fracture has been corrected.

- Paraesthesia of the distributing area due to crushing or tearing of the nerve within the infraorbital canal or foramen. Recovery of the nerve by itself may take at least 1 year.

- Limited mandibular movements are caused due to a depressed zygoma impinging on the coronoid process of the mandible, restricting the free excursion of the coronoid process. Patient complains of difficulty to open the mouth, and some cases of difficulty to close the mouth may be due to an open mouth during the blow to the zygomatic complex.

- Pseudoarthrosis between the coronoid process and temporal process of the zygomatic bone may occur rarely in old untreated cases [72].

Indications for Surgery: [3]

- Aesthetically unacceptable asymmetry of the orbital rims. Pathological difference between the two malar prominences more than $5 \mathrm{~mm}$.

- Diplopia caused due to downward displacement (more than $3 \mathrm{~mm}$ ) of the eyeball due to orbital floor displacement and not primarily due to neural or muscle damage.

Table 61.3 Radiographic assessment for detecting malunion at fracture sites

\begin{tabular}{|c|c|}
\hline $\begin{array}{l}\text { Type of } x \text {-ray/ } \\
\text { view }\end{array}$ & Use \\
\hline $\begin{array}{l}\text { Occipito-mental } \\
\text { (Waters View) }\end{array}$ & $\begin{array}{l}\text { To examine fronto-zygomatic suture, inferior } \\
\text { orbital rim and maxillary sinus }\end{array}$ \\
\hline $\begin{array}{l}\text { Postero-anterior } \\
\text { view }\end{array}$ & To examine orbital floor and rim \\
\hline $\begin{array}{l}\text { Vertico- } \\
\text { submental }\end{array}$ & $\begin{array}{l}\text { "Jug-handle" appearance. To view zygomatic } \\
\text { arch }\end{array}$ \\
\hline Tomograms & $\begin{array}{l}\text { To examine orbital floor, space between coronoid } \\
\text { process and zygomatic arch }\end{array}$ \\
\hline CBCT & $\begin{array}{l}\text { To obtain and study oblique images from the } \\
\text { three-dimensional data for fracture detection, } \\
\text { displacement evaluation, soft tissue herniation }\end{array}$ \\
\hline
\end{tabular}

- Enophthalmos in combination with displacement of the orbital floor.

- Paraesthesia of the orbital nerve after at least 12 months of post-surgical repositioning of bone fragments.

- Depression of zygomatic arch impinging the coronoid process that is radiographically evident in causing limited mandibular movement.

Surgical correction of traumatic zygomatic complex fractures is discussed in Chap. 56.

Treatment options: [3] (Chart 61.6) (Table 61.4)

Surgical approach is decided once the operative procedure has been finalised. Common approaches include [3]:

- Periorbital (Chart 61.7)

- Preauricular (Chart 61.7)

- Oral (Chart 61.8)

- Old facial scar

Complications: [3]

- Failed surgery due to insufficient fixation of the refractured site or failure due to the implanted materials.

- Untreated pre-existing chronic sinusitis may result in an orbital abscess or phlegmon.

- Serious complications that may lead to blindness.

- Fracture of bone at the optic canal

- Misplaced implant that may result in compression of nerve

- Retrobulbar haemorrhage

\subsubsection{Secondary Orbital Reconstruction $[5,72,73]$}

Post-traumatic secondary deformities include:

- Enophthalmos

- Dystopia

Both deformities are difficult to correct.

Factors Responsible for Globe Malposition:

- Displaced or missing periorbital bone

- Orbital fat loss

- Contracture of scar

Factors Responsible for Enophthalmos:

- Pathological increase in bony orbit

- Dislocated zygomatic bone

Rotated and displaced zygomatic bone leads to separation of the structures from its normal articulation with the greater wing of the sphenoid and maxilla. A substantial increase in the volume of the orbital cavity is accompanied by fissures along the floor and lateral wall of the orbit. Also, nasoethmoidal fractures can result in canthal distortion and mal- 
Chart 61.6 Treatment

options for residual zygomatic

complex deformities
Chart 61.7 Treatment options for residual zygomatic complex deformities-Preauricular and periorbital approach

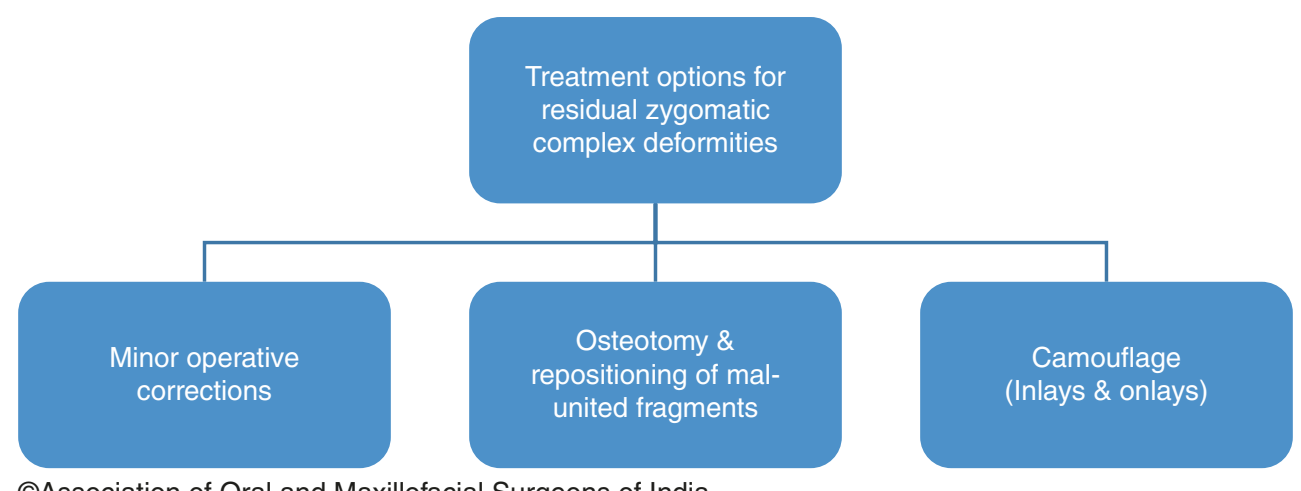

CAssociation of Oral and Maxillofacial Surgeons of India
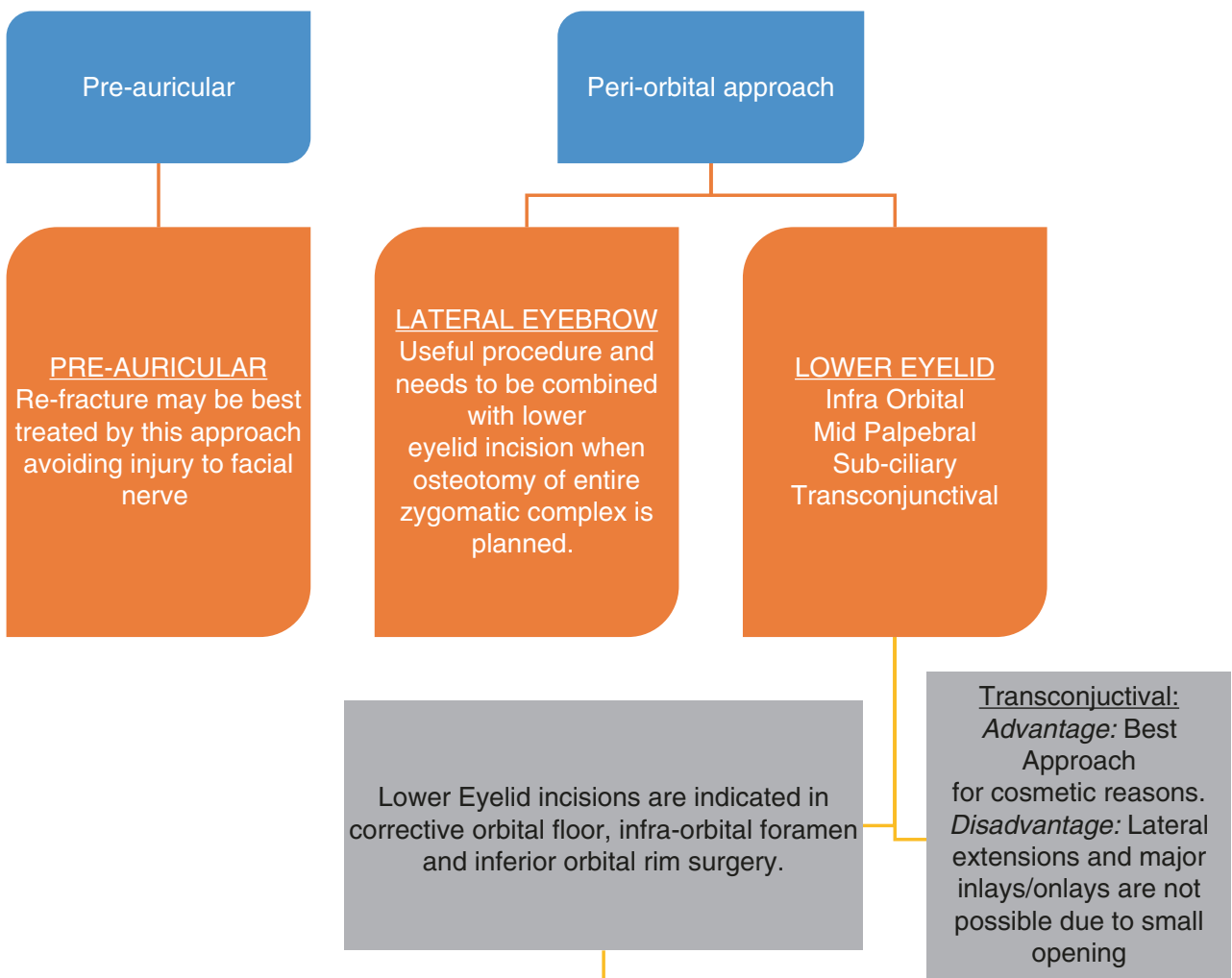

Infra Orbital incision: Routine procedure.

Subciliary incision is chosen in selected cases but rarely causes unaesthetic outcomes.

CAssociation of Oral and Maxillofacial Surgeons of India position. Telecanthus and canthal height distortion can be difficult to correct if there is a significant loss of soft and hard tissue.

Any excess or deficiency in the horizontal position of the globe is called dystopia and is easier to correct. Inferior displacement (horizontal displacement) is managed by aug- menting the sub-periosteum of the anterior orbital wall, anterior to the axis of the globe. This technique helps to produce superior movement of the eyeball but does not correct enophthalmos even with the overall decrease in orbital volume [5]. 


\section{Chart 61.8 Treatment}

options for residual zygomatic

complex deformities-Oral

approach

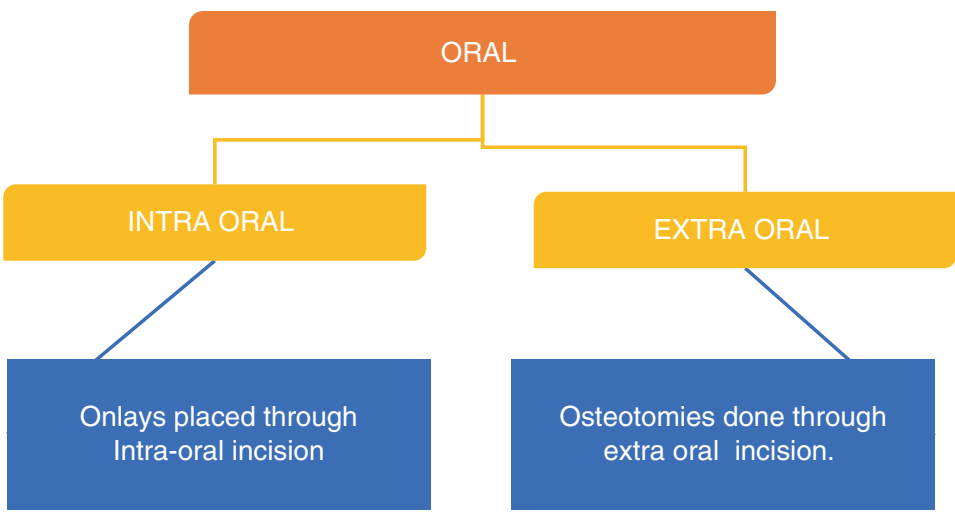

Orbital floor reconstruction

(If necessary)

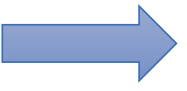

Two Accesses will be

needed: Peri Orbital

\& Intra-Oral Incision

CAssociation of Oral and Maxillofacial Surgeons of India

Table 61.4 Surgical options for zygomatic residual fractures [3]

\begin{tabular}{|c|c|c|}
\hline Indications & Clinical presentation & Treatment \\
\hline \multirow{3}{*}{$\begin{array}{l}\text { Removal or } \\
\text { reposition of } \\
\text { mal-united } \\
\text { fragments }\end{array}$} & $\begin{array}{l}\text { - Sequelae of old, mal-united and } \\
\text { consolidated fracture of } \\
\text { zygomatic complex }\end{array}$ & Corrective surgery considered \\
\hline & $\begin{array}{l}\text { - No disturbance to intercuspation } \\
\text { and occlusion } \\
\text { - No abnormal ophthalmic findings } \\
\text { - Good overall symmetry and } \\
\text { harmony of the face }\end{array}$ & No major osteotomy is indicated \\
\hline & $\begin{array}{l}\text { - Visible bony step at the orbital } \\
\text { rim }\end{array}$ & $\begin{array}{l}\text { Surgically removed through lower eyelid incision. } \\
\text { During this, the orbital floor needs to be observed for any adhesions }\end{array}$ \\
\hline Paraesthesia & $\begin{array}{l}\text { - Persistent paraesthesia is an } \\
\text { indication for surgery }\end{array}$ & $\begin{array}{l}\text { Infra orbital foramen is widened to free the nerve } \\
\text { When only paraesthesia is present—can be accessed through an intra oral approach } \\
\text { When additional exploration of the infra orbital canal is required-lower eyelid } \\
\text { incision is indicated }\end{array}$ \\
\hline $\begin{array}{l}\text { Depressed } \\
\text { Zygomatic arch }\end{array}$ & $\begin{array}{l}\text { - Hindering the coronoid process' } \\
\text { free excursion }\end{array}$ & $\begin{array}{l}\text { Refracture, reposition and wire fixation } \\
\text { Surgical Approach: Curvilinear, pre-auricular and/or lateral eyebrow incision } \\
\text { Older surgical approach: Removal of coronoid process }\end{array}$ \\
\hline \multirow[t]{3}{*}{$\begin{array}{l}\text { Complete Zygoma } \\
\text { Dislocation }\end{array}$} & $\begin{array}{l}\text { Depressed malar prominence, } \\
\text { caudally displaced eyeball and } \\
\text { diplopia }\end{array}$ & $\begin{array}{l}\text { - Treated with osteotomy } \\
\text { - Camouflage surgery as a second option } \\
\text { - Lateral eyebrow incision and infra-orbital incision to explore the zygomatic } \\
\text { complex and detach from the frontozygomatic suture at the inferior orbital } \\
\text { margin, inferior and lateral walls of the orbit, and the zygomatic arch (if } \\
\text { necessary) } \\
\text { - Reposition the segments } \\
\text { - Fixation of the fragment is further assured by placing bone graft in the gap in } \\
\text { lateral or inferior orbital rim } \\
\text { - Orbital Floor is finally covered with lyophilised dura. Procedure is done to ensure } \\
\text { good support to the malar bone and orbital floor }\end{array}$ \\
\hline & $\begin{array}{l}\text { - To prevent post-operative relapse } \\
\text { after above surgery }\end{array}$ & Over compensate the pre-operative displacement to a certain extent \\
\hline & $\begin{array}{l}\text { - If downward displacement of } \\
\text { globe is not completely resolved } \\
\text { after the surgery. }\end{array}$ & Free transplant of lyophilized dura could be an option \\
\hline
\end{tabular}




\section{Enophthalmos: [5]}

Managing post-traumatic secondary enophthalmos involves reducing the volume of orbital cavity posterior to the globe axis. The three-dimensional anatomy of both external and internal structures of the bony orbit should be restored efficiently by refracturing and rearticulating the skeletal framework (including zygomatic bone).

- The zygomatic bone may be accessed by complete exposure using surgical techniques to free the bone and also to establish the correct alignment.

- The zygomaticofrontal suture and the zygomatic arch are exposed through the coronal flap, and facial and muscular connections including the masseter muscle are released.

- Inferior orbital rim and orbital floor are exposed through a lower eyelid incision. Upper lip gingivobuccal incision is done to uncover the zygomatico-maxillary articulation.

- Bony cuts mimicking zygomatic complex fracture are made with a reciprocating bone saw.

- The zygomatic bone is freed and then replaced into the new position with rigid fixation. Necessary bone grafting needs to be done to close the gaps and also to augment the orbital volume.

- The globe should be left slightly exophthalmic (1-2 mm). If an autologous bone is used in augmenting the orbital volume, this exophthalmos is left behind expecting resorption over the next few months. However, this may be difficult to achieve in cases of excessive scarring.

- Placement of the graft plays a very important role as improper placement of grafts, or displacement into the intramuscular cone can result in dysfunction of the extraocular muscles or damage/injure the optic nerve.

- Management of complication: Creating safe pockets for the graft by carefully dissecting off the periorbita from the underlying bone. The grafts may be placed external to the extraocular muscles if the periorbita had been disrupted from previous trauma.

- Enophthalmos and diplopia may worsen further due to scarring or displacement of the implant. However, postoperatively globe position may moderately improve and is often long-lasting [5, 72-74].

Complications in Correction of Enophthalmos: [12, 74]

- Worsening vision.

- Diplopia-may improve to certain degree.

- Dystopia.

- Persistent enophthalmos.

- Graft displacement/retrobulbar hematoma may result in changes in vision.

- Pressure from grafts posterior to the globe may result in retinal folds and ischemia.
Telecanthus: [74]

- Lateral displacement of the medial canthus is called telecanthus.

- Corrected using medial orbital osteotomy by positioning the tendon and the overlying soft tissue medially.

- Bone cuts that are made along the fracture lines (typical as in nasoethmoid complex fractures) help to free bone segment that inserts into the point of the tendon, followed by medially relocating the bone to its normal anatomical location.

- Rigid fixation of the bone is done to the surrounding bone over the maxilla and inferomedial forehead. Autologous bone grafts may be used to replace missing bone segments.

\subsubsection{Nasal Deformities $[3,75]$}

Residual nasal deformities occur as a consequence of the displacement of bony and cartilaginous components of the nasal skeleton. The basic anatomy of the nasal skeleton includes the nasal bone and the cartilaginous part of the nasal septum. The frontal process forms the lateral walls, and the vomer forms the osseous part of the nasal septum. The nose is the most commonly traumatised area due to its prominent central location and its elevation from the frontal facial plane. However, secondary deformities to nasal trauma are not rare [3].

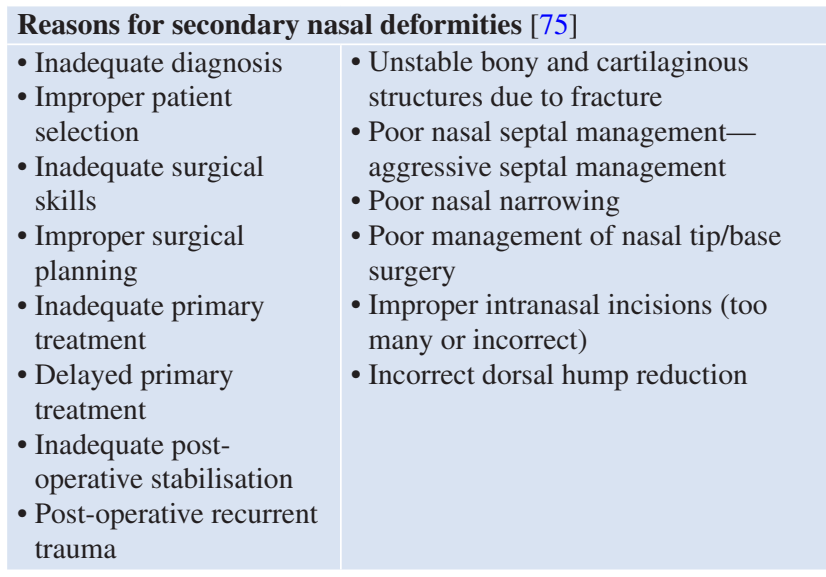

\subsubsection{Potential Complications Associated with Nasal Deformities [3] (Chart 61.9)}

Clinical Evaluation: [3, 75]

The patient needs to be aware and educated on the options for a secondary rhinoplasty to correct the residual nasal deformities as the pathology may concern the functional and cosmetic needs of the patient. 
- The intensity of the trauma is relative to the type of deformity that may follow.

- Initial low intensity trauma $\rightarrow$ nasal tip may become malpositioned. There is an evident inward rotation of the lower portion and an upward-outward rotation of the upper portion. This results in a depressed supra tip and a small cephalic hump.

- Increased force $\rightarrow$ fracture of the bones, cartilage or the nasal dorsum

- Incomplete fracture $\rightarrow$ late deviation

Preoperative Examination: [3]

- Identify the aesthetic and functional concerns of the patient

- External examination of the nose and the face as a whole

- Deformity

- Symmetry

- Internal examination with endoscope and speculum

- Airway examination

- Radiological examination to aid in diagnosis

Morphological Considerations: [3]

- Profile:

- Shape/contour

- Prominence of the nasal bridge

- Symmetrical position: Position and relation with the naso-orbital angles

- Degree of angulation and contour of frontal and the nasal margins at nasofrontal angle

- Evaluation of naso-labial angle

It is important to evaluate the injury as it may be related to [3]

- Exterior framework

- Posterior ethmoidal maxillary bony base

- Superior fronto-ethmoidal complex Residual deformities may fall in the following groups and are discussed in brief

- Deformities of the nasal bridge or nasomaxillary region.

- Deformities of the naso-orbital angle or naso-ethmoidal region.

- Deformities associated with nasofrontal angle.

- Complex deformities involving the naso-ethmoido-frontal complex.

\subsubsection{Deformities of the Nasal Bridge or Nasomaxillary Region [3]}

Deformities involving the nasal bridge and lateral walls of the nose not extending into the frontal or orbital regions.

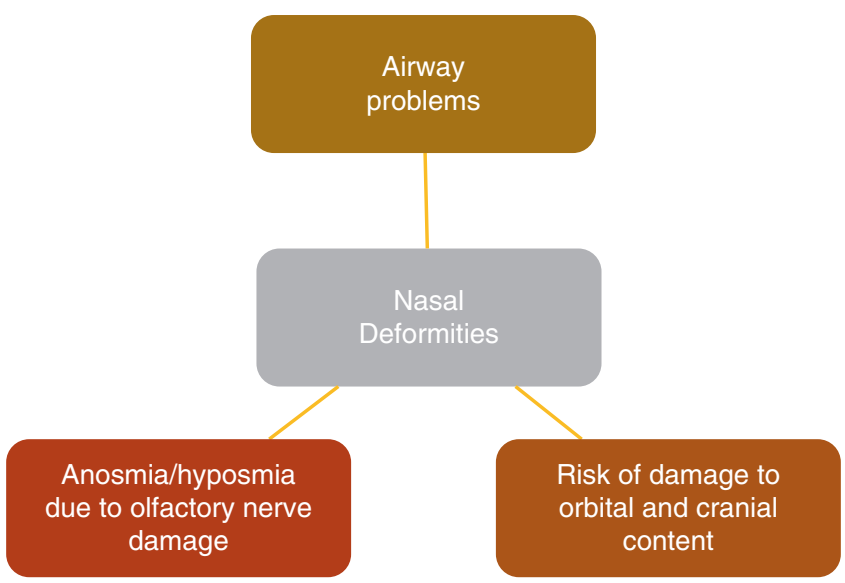

CAssociation of Oral and Maxillofacial Surgeons of India

Chart 61.9 Potential complications associated with nasal deformities

Pathogenesis:

- Fractures of $\rightarrow$ nasal bone, frontal process of the maxilla, septal cartilage $\rightarrow$ untreated and/or inadequately treated fractures, displaced fragment $\rightarrow$ resorption associated with fibrous union/malunion with excess callus formation.

- Malunion depends on the direction and point of contact of the blow of the original injury.

- Residual callus and subsequent deformity will be evident following fracture of bony or cartilaginous structures or both tissues.

- Force directed from the lateral aspect $\rightarrow$ deviation of the bridge and lateral wall to the opposite side.

- Force $\rightarrow$ antero-posterior plane $\rightarrow$ depression of the nasal bridge and crushing of associated supporting posterior bony elements.

- Blow from the lateral aspect $\rightarrow$ displacement or bent/ twisted nature of the nasal septum $\rightarrow$ one surface of the septum is therefore outwardly bent $\rightarrow$ airway obstruction.

- Impact $\rightarrow$ antero-posterior or sagittal plane $\rightarrow$ telescoped or folded septum $\rightarrow$ reduces nasal patency $\rightarrow$ obstruction of airway

Clinical Features:

- Obvious external deformity-aesthetic concern for the patient.

- Nose deviated towards one side or crushed inwards or both deformities together.

- Deviation $\rightarrow$ curvature of the septum.

- When seen from the front, the bridge and the dorsum of the nose may appear to be in a straight line, but the tip and the base of the septum are deviated, also leading to deformation of the nasal orifice. 
Nose:

- Convex on one side (or) upper half/lower half-convex, another half-concave.

- Tip of nose may often be straight but is angulated when the cartilaginous dorsum is displaced.

- Profile-straight or depressed along the entire length/ depression confined to nasal prominence (upper or lower half).

- Malunion of septal component-deformity leading to alteration in patency of the nasal airway.

- Narrowing of patency-Unilateral or bilateral $\rightarrow$ ultimately leads to obstruction.

- Nasal disturbances-Important to evaluate with age, occupation, pre-existing illness or any pulmonary pathology.

- Nasal airway disturbance $\rightarrow$ may lead to complications of airway tract and paranasal sinuses.

- Depression of nose-depression along the entire nasal crest or depression involving only the lower half.

Surgical Approach for nasal deviation:

- Intranasal approach for aesthetic rhinoplasty - this avoids any external cutaneous scars.

- Dissection is done by Separating or freeing the external investing tissues $\rightarrow$ elevation of mucous membrane that lines the nasal fossae.

- Dissection includes separation of underlying soft tissues and separation of mucosa.

- Bony and cartilaginous structures freed from the external and internal harvesting tissues.

- This is followed by chondrotomies and osteotomies.

- Chondrotomies are done to mobilise the septal cartilage.

- Osteotomies are done to reduce the displacement of the nasal bridge and dorsum - lateral and median osteotomy.

- Immobilisation aids in maintaining the fragments in position during the union. Careful immobilisation is done internally and externally.

\subsubsection{Depression of Nose [3] (Saddle-Shaped Deformity)}

Treatment differs based on extent of the deformity along the nasal crest (entire length or lower half).

- This deformity is best treated with placement of a bone graft in the region of depression of the bone.

- Intranasal: Best indicated surgical approach but less nasal exposure is a disadvantage.

- Vertical columella incision: Gives good exposure but may leave scars.

- A combined incision with both internal and external incision gives best exposure and leaves a less obvious transnasal scar in the anterior one-third of columella. This is almost invisible in the upright position due to its presence in a "dead angle".
- Surgical steps involve preparation of bony bed at receptor site and preparation of bone graft for placement.

- Stabilisation of bone graft by firm fixation in median, vertical and sagittal planes. Ensure the maintenance of columnar support.

- Sutures placed with adequate immobilisation.

\subsubsection{Depression of Lower Half of Nasal Crest [3]}

Two types of concepts are followed in treatment of such deformities:

- Reduce false or relative prominence by resection of upper half of the nasal crest. Nasal profile is converted to being straight. This might increase the width of the upper half of the nasal crest for which osteotomy of lateral walls may be essential. This concept is to be applied when adequate nasal bone is available to produce a healthy and aesthetic profile.

- The other concept involves the placement of a cartilaginous graft to cover the depression. Fixation may however be difficult in this scenario.

\subsubsection{Naso-Orbital Deformities [3]}

Deformities not only involving the nasal pyramid but also affecting the ethmoid and maxillary components.

Pathogenesis:

- Severe impact $\rightarrow$ nasal complex $\rightarrow$ results in extension of fracture lines and displacement of associated components.

- Deformities may extend into the frontal process of the maxilla and the two orbital plates of ethmoid bone (which support the nasal bones).

- Due to the complex anatomy of this region, various combinations in deformities, fracture pattern, injury and pathology may be seen.

Anatomical Characteristics: [3]

Frontal process of the maxilla-

- Determines the morphology of nasal pyramid.

- Determines the orbito-nasal angle

- Forms the lacrimal fossa (anterior part)

- Serves as a point of insertion for the medial palpebral ligament in the anterior crest

\section{Ethmoid bone-}

- Determines the formation of lacrimal canal on lateral aspects.

- Continues posteriorly as the orbital plate which forms the medial wall of the orbit.

- Contributes to the formation of the posterior part of the nasal septum.

Clinical Features:

Nasal crest- 
- Deviated or often depressed $\rightarrow$ consequent lateral displacement or antero-posterior crushing of the nasal bones. Orbito-nasal angle-

- Reduced/obliterated/displaced outwards Widening of bridge-

- Due to displacement of frontal processes of the maxillae outwards and backwards

- Due to malunion of a comminuted type of fracture. Displacement of medial canthus-

- External displacement may produce telecanthus.

- Anterior displacement will further increase in obliteration of the orbito-nasal angle.

- Inferior dystopia-vertical displacement deranges the symmetry of two medial canthi.

- Dystopias are due to the bony fragments impinging on the tissues and causing rupture of the medial canthal ligament, avulsion of the ligament and displacement of frontal process of maxilla which houses the medial canthal ligament. Lacrimal passages-

- The lacrimal canal is blocked due to discontinuity in nasolacrimal apparatus. Bony fragments of comminuted fractures may cause tearing of the lacrimal sac. This may result in epiphora.

- Epiphora $\rightarrow$ watering of eyes $\rightarrow \rightarrow$ dacryocystitis. Nasal airway patency problems due to -

- Deviation of posterior part of nasal septum.

- Blockage caused by nasal septum may further be accentuated by displacement of anterior cartilaginous part of the nasal septum.

\section{Essentials in Correcting the Deformity:}

- Repair the base of the nose.

- Repair the naso-orbital angle.

- Restore the lacrimal passages.

- Nasal reconstruction must be carried out while correcting the above mentioned during the same procedure.

\subsubsection{Surgical Management}

Key Points in Treatment:

- Reconstitution of the nasal base is the basic procedure in reconstruction of the nasal pyramid. It has to be supported by a solid base.

- Base has to be aesthetically appealing, smooth, regular and well proportioned.

- Reconstitution of the naso-orbital angle is essential.

- Symmetrical placement of the two medial canthi is necessary. Any asymmetry can affect the appearance of the nose.

- Approach to the lacrimal passages may be obtained by dividing the medial canthal ligament that can be reattached later.
- Quality of repair is subsequently affected in cases of infected lacrimal passages.

- Any deviation of the nasal septum negatively influences nasal reconstruction.

\subsubsection{Nasofrontal Deformities [3]}

Deformities due to secondary post-traumatic lesions involving not only the nasal pyramid but also the nasal base and area of the frontal bone. Concentration of injuries at the nasofrontal angle is proportionate to the degree of violence encountered, thereby resulting in fractures and displacement of tissues.

Nasofrontal angle profile is affected by

- Frontal region (median)

- Paranasal region (inferior)

- Secondary malunited callus

\section{Pathogenesis:}

- Trauma $\rightarrow$ nasal spine of frontal bone $\rightarrow$ displacement of nasal spine involving middle part of the inferior wall or floor of the sinus

- Trauma $\rightarrow$ anterior wall of sinus $\rightarrow$ fracture extending into the anterior wall of sinus or posteriorly communicating with the posterior wall

Lesions on anterior wall-

- When isolated and not involving the other walls $\rightarrow$ has only aesthetic significance

- Malunited depressed fracture $\rightarrow$ hollow midline $\rightarrow$ significant reduction of the nasofrontal angle

Lesions of inferior wall-

- Depression $\rightarrow$ hollow midline $\rightarrow$ reduction in nasofrontal angle $\rightarrow$ has a cosmetic influence and also affects patency of frontonasal duct $\rightarrow$ blockage of canal $\rightarrow$ blockage of outflow tract

- Lateral aspect of lesions $\rightarrow$ involving medial portion of orbital roof $\rightarrow$ deformed naso-orbital angle $\rightarrow$ subsequent risk of spread of the infection

Lesions of posterior wall-

- Injury in this zone affects the brain and the meninges.

- Fracture $\rightarrow$ unhealed fissures $\rightarrow$ spread of infection to the meninges.

- Deformity in the continuity of bone $\rightarrow$ herniation of the brain and meninges.

- Sharp bony defect $\rightarrow$ penetrates the meninges $\rightarrow$ CSF rhinorrhoea.

Associated lesions-

- When more than one wall is involved $\rightarrow$ increased deformity of the nasofrontal angle $\rightarrow$ complications in sinus drainage, brain and meninges

- Resorption of fractured margins $\rightarrow$ loss of continuity in the anterior or posterior walls $\rightarrow$ deformed nasofrontal angle 
Clinical Features:

- Profile is altered-depression and deviation of nasal bones $\rightarrow$ unaesthetic profile of the frontonasal angle.

- Greater degree of depression is relative to the retrusion or displacement of middle frontal segment posteriorly, extending above the orbits as far as the bridge of nose.

- Resorption or loss of bony tissue $\rightarrow$ protrusion of tissue between bony margins $\rightarrow$ meningocele $\rightarrow$ increased prominence.

Associated pathological changes-

- Osteitis in fracture zone

- Improper drainage $\rightarrow$ persistence of infection

- Meningitis

- CSF rhinorrhoea

- Brain abscess

\section{Essentials in Surgical Management:}

- Morphological and functional defects should be corrected to avoid any vital injury in the future.

- In case of depression of the nasal crest and deformities involving only the anterior wall of sinus, onlay bone graft is essential to augment the defect.

- Grossly deranged sinus must be treated first and then followed by nasal reconstruction.

- Grafting is not enough when deformities involve the inferior wall/floor and/or posterior wall as it carries the risk of damaging the sinus, brain and meninges.

The principles of the management of nasofrontal deformities in delayed conditions are similar to managing post-traumatic nasofrontal deformities but should be done with caution and must address associated complications seen at the stage of delayed management. In case of nasofrontal deformities, it is important to address post-traumatic dehiscence of frontal sinus wall in delayed management cases. Certain degree of bone loss due to resorption is seen during the post-traumatic phase, and this may increase when the management is delayed. Hence, in such cases it is important to be cautious in resection of minimal tissue of the posterior wall, and it needs to be carefully performed. Reconstruction of the anterior wall with bone grafts may be done, also including the orbital roof and the ethmoidal region if necessary [3].

\subsubsection{Naso-Fronto-Ethmoidal Deformities [3]}

Deformities involving the nasal bony mass are caused due to greater degree of force. The impact may extend as far as the ethmoid bone which forms the upper wall/roof in the posterior part.

Pathogenesis:

- Fractures lines extending from the front, passing behind and across the nasal spine and extending into the cribriform plate

- Displacement due to fracture $\rightarrow$ affects the passage of olfactory nerve $\rightarrow$ further lacerates the dura mater $\rightarrow$ cerebrospinal fluid leakage or CSF rhinorrhoea

Clinical Features:

- Clinically, it may be similar to the deformities involving nasofrontal fractures. A mere extension into the cribriform plate does not increase the severity of the deformity. Features may differ based on the involvement of anterior wall.

- Anosmia-loss of smell sensation.

- If the meningeal tear is not sealed immediately $\rightarrow$ CSF rhinorrhoea.

- The meningeal tear is always predisposed with long-term risk of leak (even after the leakage has dried) due to lack in quality of scar tissue and increased permeability of the malunited callus.

\section{Essentials in Management of Naso-Fronto-Ethmoidal}

Deformities:

- Surgery may be carried out by combined neurosurgical and maxillofacial teams.

- Meningeal tear repair can be managed by trans-ethmoidal (low level) approach. However, trans-frontal approach is considered to be safer and effective.

- Sinus-associated lesions should be managed along with nasal reconstruction procedure.

- The principles of the management of naso-frontoethmoidal deformities in delayed conditions are similar to managing post-traumatic naso-fronto-ethmoidal deformities or naso-orbito-ethomoidal complex fractures but should be done with caution, addressing associated complications seen at the stage of delayed management.

\subsubsection{Delayed Management of Orbital Hypertelorism and Naso-Orbito- Ethmoidal (NOE) Fractures [73, 75-77]}

Acute trauma in the naso-orbito-ethomoidal region could result in chronic orbital and naso-orbital deformities. It is important to be aware of the acute injury to correct the defor- 
mity that will be established later. Secondary late corrections in cases of severe orbital hypertelorism may be very difficult to correct. The severity of orbital hypertelorism can be assessed with the help of Tessier score.

Traumatic orbital hypertelorism due to NOE complex fractures

Goals of management:

- Symmetrical restoration of medial canthal anatomy

- Maintenance of physiologic function of the lacrimal system

- Avoid frontal sinus-related complications

- Restoration of globe position and volume

Surgical Management:

- Coronal approach gives the most predictable access and visualisation for the surgeon.

- Frontal sinus should also be evaluated and operated at this stage.

- Reconstruction should be considered in the following order starting first with cranial base, frontal region and outer orbital zone, followed by fixation of the orbital rim and frontonasal buttress. Grafts and plates may be used to restore the nasal dorsum and nasal projection.

- It is then followed by repositioning and fixation of the mini-plate in the medial orbital wall and medial canthal tendon. Mesh and trans-nasal wiring may be used for repositioning the displaced medial canthal tendon.

- It is important to establish a good frontonasal angle and nasal projection to have good aesthetic outcome. Deformity could result in poor aesthetics when there is poor frontonasal angle and poor nasal projection along with orbital hypertelorism.

\subsubsection{Secondary or Delayed Management of Orbital Hypertelorism Associated with NOE Complex Fractures [75-77]}

- Goal is to restore the normal interorbital distance.

- Acute management of chronic long-standing deformities is essential. It is very difficult to correct severe orbital hypertelorism, especially in cases which includes intracranial osteotomies. Such cases are associated with increased post-operative morbidities. Subcranial osteotomies may be opted in milder cases.

- Aesthetic and functional outcomes in late correction may not be satisfying, and hence the best strategy is to repair the deformities as early as possible following the first injury and hence not delay the treatment.

\subsubsection{Conclusion}

- Repair and reconstruction of nasal deformities are often challenging and technique sensitive for the surgical team (maxillofacial and neurosurgical). It is emotionally and psychologically challenging for the patients as well. Hence, it is essential to identify the pitfalls and carefully carry out the surgical treatment plan. Sometimes, further revision may be necessary even with the best planned surgical procedures. Therefore, it is important for the surgeon and the patient to understand the limitations of the available surgical techniques.

\subsection{Post-oncological Deformities}

Management of Post-oncological Deformities:

Post-oncological deformities here refer to the soft tissue and hard tissue defects that may be encountered following a primary treatment. Unlike a primary cosmetic therapy, predicting the result of an oncological treatment is often more technique sensitive and should be considerate in establishing the overall physical and mental well-being of the patient. Management of deformities should also aim at a comprehensive functional, aesthetic and social well-being of the patient.

Reconstruction of soft tissue and hard tissue structures following trauma or oncological surgical therapy is primarily essential. Correction of the residual deformities should be carried out along with the principles of reconstructive management.

Reconstruction generally includes the following steps in management [78]:

- Healing by secondary intention

- Primary closure

- Grafting - split or full-thickness graft

- Composite grafts

- Local grafts

- Regional pedicle grating

- Free tissue transfer 
We have already discussed in detail the use of above methods in management of traumatic residual deformities in this chapter.

Recurrences, untreated tumours and metastasis which are considered to be residual in nature after primary management are not considered under management of postoncological deformities. It is important for the surgeons to be more accurate with the surgical margins when surgically operating malignancies. Any re-surgical procedure for recurrence or deformities is often challenging due to factors like previously irradiated areas, previously operated surgical field, under nourished status due to the pre-existing malignant condition and also due minimal surgical options for such patients.

Residual deformities associated with post-oncosurgery results in external facial disfigurement/defects, intra-oral defects and also changes that may affect certain functions. These deformities are often relative to structures which were primarily involved and their corresponding functional deformities. Deformities occurring following surgical treatment of head and neck oncology usually require reconstruction procedures as the complete removal of tumours with margins may involve increased loss of soft or hard tissues.

\subsubsection{Lip Deformities [79-83]}

Post-oncosurgical defects of the lip are often seen with loss of tissues. Management of such defects is usually considered according to the size of the defects. Secondary deformities of the lower lip after reconstruction are described in (Table 61.5), and they need to be treated accordingly with cosmetic surgeries. Lip reconstruction is discussed in soft Tissue reconstruction chap. 86.

Table 61.5 Secondary deformities of lower lip following reconstruction

\begin{tabular}{|c|c|c|}
\hline Type of Flap & Deformities & Complications \\
\hline Abbe & $\begin{array}{l}\text { Relative Microsomia } \\
\text { Trap Door deformity due to } \\
\text { thickened scar }\end{array}$ & $\begin{array}{l}\text { Vermillon notching } \\
\text { Lip asymmetry } \\
\text { Scarring beyond } \\
\text { submental crease }\end{array}$ \\
\hline Estlander & \multicolumn{2}{|c|}{$\begin{array}{l}\text { Commissure violation and may require } \\
\text { commissuroplasty }\end{array}$} \\
\hline Karpandzic & $\begin{array}{l}\text { Microstomia } \\
\text { Inversion vermillion } \\
\text { Flat mentolabial junction }\end{array}$ & $\begin{array}{l}\text { Dysthesia or Anesthesia } \\
\text { of lip }\end{array}$ \\
\hline Gillies fan & \multicolumn{2}{|l|}{ Oral incompetence may result } \\
\hline $\begin{array}{l}\text { Bernard } \\
\text { burrow }\end{array}$ & Adynamic reconstruction & Post-operative drooling \\
\hline
\end{tabular}

\subsubsection{Management of Intra-oral Defects Involving Floor of the Mouth and Alveolar Ridge Tumours}

Defects in these regions are relative to the size of tissues lost and may be corrected with augmentation and reconstruction procedures.

- Correction of small intra-oral defects is best done with primary closure in the buccal and tongue region, but scar contracture is seen with grafting. Closure by secondary intention can be done in alveolar and hard palate defects where the scar contracture is insignificant [84].

- Correction of large intra-oral defects using free flaps is considered ideal in reconstruction procedures [84-86].

- Advanced large defects may be seen in cases which require large resection of tissues, as in cases of advanced tumours which may include cortical or segmental mandibulectomy, composite resections, and glossectomy (total/sub-total) procedure. These defects may also involve the lip or skin of the lower third of the face when tumour extends anteriorly [86]. Hemi- or partial loss of mandible may result in severe functional or psychological morbidity for the patients. The loss of anterior mandible results in a defect called as "Andy-Gump" deformity [87]. En bloc resection is best reconstructed with regional free tissue transfer or free flaps. Bony defects are managed with osteocutaneous free flap or with free tissue transfer.

\subsubsection{Management of Defects of Oropharynx}

Oropharyngeal defects are managed with primary closure, skin grafts, local pedicle flaps and microvascular-free flaps. Current goals in reconstruction include restoration of the function and closure of defects as well.

\subsubsection{Management of Soft Palate Defects [88]}

- Soft palate defects cause velopharyngeal incompetency resulting in inability to seal the oropharyngeal and nasopharyngeal cavity during speech and deglutition.

- Rhinolalia aperta is caused due to small soft palate defects leading to change in resonance of voice as a result of air escape due to incompetent velum.

- Smaller defects are best closed primarily or along with a split-thickness skin graft.

- Radial forearm flaps are used in cases following surgical ablation of soft palate and tonsillar defects. 
- Large or extensive palatomaxillary defects are managed with obturator prosthesis or with vascularised osteocutaneous free flaps.

\subsubsection{Management of Tongue Defects [89, 90]}

Tongue defects are usually difficult to treat and reconstruct. Management of tongue defects primarily involves improving the functional outcome.

- Small defects are managed with primary closure.

- Large defects are treated with myocutaneous flaps (rectus or pectoral major flaps and fasciocutaneous flaps)

\subsubsection{Management of Posterior Pharyngeal Wall [90]}

- Primary closure with/without split thickness skin graft is used for closure of small defects. Free flap reconstruction is necessary for large defects.

\subsubsection{Deformities Associated with Intra-oral Disfigurement [91-98]}

The primary goal in surgical management of oral tumours is to gain surgical access for assessment and visualisation of margins and anatomic relations for resecting the tumours. Surgical margins are vital in establishing a tumour-free zone. Although it is important to have a follow-up on recurrence of tumours and metastasis, it is the complex nature of the oral cavity and head and neck anatomy that requires careful yet skilful management of the adjacent normal tissues by proper closure and post-operative management.

The goal earlier was to achieve access to the tumours, but now it also involves incisions that will facilitate an aesthetic access to the pathology. Increased incidence of dehiscence and unaesthetic scar formation are common in neck incisions (with trifurcation extensions) that do not lie along the natural skin creases. Irradiated areas may cause worsening of scar appearance, or even superficial necrosis may occur. Inadequate, delayed and infected tracheostomy may also result in an unaesthetic tracheostomy scar formation. Prevention of unaesthetic scars can be done by careful tissue handling. It is also essential to protect the skin from additional trauma due to traction, tension or electrocautery. Flaps with adequate vascularity further help to minimise the chances of unaesthetic scars. Following access through the lip to certain tumours in the oral cavity, the site requires to be exactly oriented and aligned with the vermilion lip border, as well as interdigitating orbicularis oris muscle, re-orienting lip skin and oral mucosa to replicate lip competence, aesthetics and function [92-97].
Even though reconstruction of maxillectomy defects is an option, maxillary defects can also be corrected with prosthetic obturators. Maxillary obturator provides adequate structural support to preserve speech, swallowing and essential mastication. Clinically, a good obturator can be fabricated only by the skills of a good prosthodontist [98].

It is important to evaluate any history that may contribute to poor wound healing and also lead to post-operative wound dehiscence and compromised flap vascularity resulting in improper scarring.

\subsubsection{Deformities Associated with Healing Tissues $[91,92,99,100]$}

Surgical procedure involving the upper aerodigestive tract through neck incision may lead to fistula formation as a result of salivary leakage.

The formation of fistulas is contributed majorly due to:

- Incision design

- Tumour type

- Tumour stage

- Improper surgical site management

- History of operative site

- Physical and nutritional status of patient

Biological Factors that Contribute to Fistula Formation:

- Effect of radiation on surgical wound closure: Radiation dose and timing play an important role in delayed wound healing, formation of fistula and dehiscence.

- Low oxygen tension: Proportional to flap vascularity and viability.

- Vascularity: Decreased blood supply affects the wound healing property.

Signs and Symptoms of Fistulas:

- Occurs post-surgery as early as 1 week and somewhere between 3 and 4weeks in late cases of fistula formation. Persistent fistulas are present for more than 1 month.

- Low-grade fever.

- Inflamed and indurated areas of skin that facilitate the drainage.

Management:

- Early assessment of fistula can help to explore the surgical wound and aid in directing saliva from vital structures.

- Site may be explored, irrigated and closed. This is followed by antimicrobial therapy and nutritional support.

- Persistent fistulas are managed with excision of the fistulous tract with closure of oral mucosa and/or skin. 
- Hardware failure due to infection can be managed with local debridement, removal/replacement of existing failed hardware and closure with local and regional flaps.

- Management can be combined with anti-cholinergic medications to decrease salivary flow if necessary and only if indicated.

\subsubsection{Functional Deformities Associated with Oro-Oncological Surgery}

Surgical cancer resection may cause the following functional defects [101]:

- Difficulty in speech, swallowing and chewing

- Difficulty in masticatory function and nutrition

- Neurological complications

\subsubsection{Spinal Accessory Nerve}

Iatrogenic injury may cause "shoulder syndrome", for which physical therapy may help to improve the functional outcome. Pain, weakness of muscles, restrained shoulder movement, deformity of the upper extremity and inability to abduct upper extremity above 90degress occur due to denervation of trapezius muscle [91, 92, 102, 103].

\subsubsection{Phrenic Nerve}

Iatrogenic damage causes paralysis of ipsilateral diaphragm. It may even result in long-term pulmonary complications. Such damage can be prevented by limiting surgical dissection to the layer superficial to pre-vertebral fascia and thereby prevent injury to nerve $[92,101,104]$.

\subsubsection{Hypoglossal Nerve and lingual Nerve}

$$
[92,101,104]
$$

- Iatrogenic damage to both the nerves is possible during head and neck dissection. This is aggravated with damage to lingual nerve during excision of tongue and floor of the mouth. Hypoglossal and lingual nerves are often preserved unless there is extensive neural invasion of the tumour.

- Hypoglossal nerve dysfunction/damage causes deviation of tongue to ipsilateral side of injury, tongue biting, dysarthria and difficulty in mastication and deglutition. Bilateral nerve injury may result in upper airway obstruction when the patient is in supine position. Atrophy of tongue muscles may also be observed.

- Damage to lingual nerve may cause ipsilateral loss of sensation, further impacting mastication, speech and swallowing. Injury to tongue during speech and mastication may also be observed.
- Rehabilitation by physical therapy is often useful for improving the speech and swallowing.

\subsubsection{Vagus Nerve, Recurrent Laryngeal Nerve and Superior Laryngeal Nerve [91]}

- Injury to these nerves may occur during dissection around the carotid sheath.

- Injury to recurrent laryngeal nerve causes unilateral vocal cord paralysis. The damage is usually compensated by the intact contralateral vocal cord. Mild hoarseness is experienced by the patient. Upper airway obstruction is seen with bilateral injury.

- Injury to branches of superior laryngeal nerve occurs due to dissection around the superior thyroid branch of external carotid artery. The following changes may be associated:

- Minor swallowing difficulty

- Decreased sensation in laryngeal inlet

- Decrease in tensor capability of true vocal cord

- Fatigue

- Decreased ability to reach high phonated/pitched sounds

Management usually begins with accurate diagnosis of the neurological origin. It is best to prevent such injuries with careful dissection.

\subsubsection{Sympathetic Trunk $[92,101,104]$}

Damage or disruption to the sympathetic trunk can result in ipsilateral Horner's syndrome. Careful evaluation is necessary to diagnose Horner's syndrome due to damage of nerve fibres, and it involves the following:

- Blepharoptosis (drooping of upper eyelid)

- Miosis or pupillary constriction

- Lack of perspiration of forehead skin

- Enophthalmos

- Vascular dilation (ipsilateral to injury)

\subsubsection{Marginal Mandibular Branch of Facial Nerve $[92,105]$}

Injury to This Nerve Causes:

- Altered mobility of corner of the mouth as a result of disruption in innervation to orbicular oris and depressor anguli oris.

- Inability to control lower lip movements during liquid consumption.

- Functional and cosmetic disturbances are seen.

Management:

Careful design and incision considering the anatomic location of the nerve during flap elevation help to prevent 
iatrogenic injuries and resultant deformities. It may take several months for neurosensory recovery when the neurologic injury is due to traction and not due to severance.

\subsection{Recent Advances}

\subsubsection{Endoscopy in Residual Deformitites} $[106,107]$

Recent trend in oral surgery includes the use of an endoscope to facilitate oral and maxillofacial procedures. Endoscopy techniques can be used in diagnosis and for treatment with minimal complications in many oral and maxillofacial surgical procedures like TMJ disorders, pathologies of jaw, nasal deformities, trauma and aesthetic procedures. The techniques and applications of endoscopy in oral and maxillofacial surgery are explained in detail elsewhere in this book. The advantages and applications of endoscopy-assisted maxillofacial surgical procedures make its usage a favourite option for maxillofacial surgeons. Minimal complications, good success rates and its efficiency make endoscopy-assisted procedures a viable option.

The following are the best-known applications of endoscopy currently in oral and maxillofacial surgery:

- Trauma

- Orthognathic deformities

- Obstructive salivary gland pathology

- Maxillary sinus surgery

- Trigeminal nerve injury

- Temporomandibular disorders

- Nasal deformities

- Trauma

Endoscopy-assisted minimally invasive technique is used in traumatic deformities like the following:

Orbital Floor Fracture: Requires trans antral approach. Care should be taken to protect the intraorbital contents like musculature, periorbita and optic nerve. Intraoperative conditions may necessitate the need for an additional periorbital approach during the surgery.

Mandibular Angle Fracture: Here, endoscopy can be used to fix the mandible with the superior and inferior plate with the best approximation possible. Endoscopic reduction helps in complete visualisation of the entire fracture line with inclusion of the inferior border. Management with endoscopyassisted surgery also reduces the risk of facial nerve injury. A single transbuccal trocar technique is used for positioning and fixation of the plates with easy visualisation of the fracture line. Some surgeons prefer a locking cannula for the precise placement of the fixation hardware. Endoscope is then used to confirm proper fixation and reduction, and it is then closed. Endoscope also aids in appropriate documentation of the procedure.

Sub-condylar Fractures: (Refer Chap. 54 on endoscopic approach for treatment of condylar fractures of mandible) Endoscopy can be applied in management of sub-condylar fractures by open technique, reducing risks of scars, fistula formation and facial nerve injury. Extra-oral and transoral approach may also be used. Although the procedure is technique sensitive, it is proposed with advantages of improved visualisation, magnified field of view, less trauma to tissues, less bleeding, better patient compliance, good reduction and decreased post-operative complications.

Frontal Sinus Fractures: Endoscopy in the management of frontal sinus fractures helps to avoid large incisions and its associated complications like alopecia, paraesthesia, scarring, nerve injury, etc. It helps in better visualisation of sinus wall fractures, nasofrontal duct and the posterior wall of sinus.

- The use of endoscopy in orthognathic surgery helps to visualise aspects of the osteotomy so as to improve the efficiency of the surgical outcome.

- Best application of endoscopy in salivary gland pathologies is the usage of sialoendoscopy in the diagnosis and treatment of salivary gland/ductal pathologies in a noninvasive manner.

- TMJ arthroscopy is another area that has gained greater attention.

- Endoscopy is also best utilised in removal of foreign bodies from the cranio-maxillofacial region as it allows visualisation of anatomical structures without extensive incisions.

Endoscopy in nasal deformities: is a developing concept, and there has been an increase in its extensive usage in sinus endoscopic surgeries. The use of endoscope in correction of septal deformities like deviation, aids in better visualisation of the target site and reduced time of the procedure. The primary advantages are improved field of view, reduced morbidity, decreased post-operative swelling and more accuracy in surgical procedure. Endoscopy in nasal corrections is very essential in cases that have gone for prior septal cartilage resection, reducing the need for repeated incisions or extent of dissection. Studies also suggest lesser post-operative symptoms in endoscopic-assisted nasal septal corrective surgeries [107]. 


\subsection{Conclusion}

Careful planning, eminent skills and excellent knowledge of the clinical anatomy are of utmost importance in carrying out secondary corrective procedures in treating residual deformities following trauma or oncological procedures. It is the skill of the surgeon to predict the functional and aesthetic outcome of the treatment so as to facilitate a proper treatment planning. It is also the role of the surgeon to educate the patient about the condition and options available for the correction, to provide the best possible outcome. It is recommended that surgeons use available imaging techniques (routine X-rays, CT scans, CBCT, etc.) in their treatment plans and also make best usage of the current trends in $3 \mathrm{D}$ models and visual planning software in treatment planning. The use of CAD/CAM-designed patient-specific alloplastic (e.g. Medpore, PEEK) implants should be considered in surgical management. Treatment plan should often accommodate recommendations from other specialities that may be a part of the surgical team.

Both soft tissue and hard tissue deformities should be dealt together in a well-planned manner to provide the patient with an acceptable aesthetic outcome and functional rehabilitation. Likewise, mastication and prosthetic rehabilitation can be aided by dental and zygomatic implants. Most often correction of residual deformities may go together with reconstruction of the lost structures. It becomes essential to carry out the entire treatment phase in a well-planned manner to provide the patient with a final, socially and psychologically acceptable outcome with or without post-operative physical therapy. Surgeons are also recommended to be updated about endoscopy-assisted surgeries and transoral robotic surgeries to further enhance the quality of outcome of the treatment.

\section{References}

\section{Introduction}

1. Ranganath K, Hemanth Kumar HR. The correction of posttraumatic pan facial residual deformity. J Maxillofac Oral Surg. 2011;10(1):20-4.

2. David DJ, Abott JR, Jay M, Nugent MAC. Deformities, textbook of craniomaxillofacial trauma, Chap. 21. New York: Churchill Livingstone; 1995. p. 545-618.

3. Evans AJ, Burwell RG, Merville L, Pfeifer G, Gundlach K, Sailer HF, et al. Residual deformities. In: Rowe NL, Williams JL, editors. Maxillofacial injuries, vol. 2. Edinburgh: Churchill Livingstone; 1985. p. $765-868$.

4. Ardeshirpour $\mathrm{F}$, et al. Improving posttraumatic facial scars. Otolaryngol Clin N Am. 2013;46(5):867-81.

5. Dolan R. Facial plastic, reconstructive and trauma surgery (Textbook). 2016 Apr. p. 716-29.
6. Hoffmann JF. Tissue expansion in the head and neck. Facial Plast Surg Clin North Am. 2005;13(2):315-24.

7. Van Rappard JHA, Molenaar J, Van Doorn K, Sonneveld GJ, Borghouts JMHM. Surface are increase in tissue expansion. Plast Reconstr Surg. 1988;82:833-7.

8. Kane WJ, McCaffrey TV, Wang TD, Koval TM. The effects of tissue expansion of previously irradiated skin. Arch Otolaryngol Head Neck Surg. 1992;118:419-26.

9. Kabaker SS, Kridel RWH, Krugman ME. Tissue expansions in the treatment of alopecia. Arch Otolaryngol. 1986;112:720.

10. Gibson T. The physical properties of skin. In: Converse JM, editor. Reconstructive plastic surgery, I. Philadelphia, PA: WB Saunders; 1977. p. 70-7.

\section{Grafts in Residual Deformities}

11. Hupp JR, Tucker MR, Ellis E. Contemporary oral and maxillofacial surgery, 6th ed. 2014.

12. Labres XR, Camps AR, Salas EJ, Albuquerque R, Ortega EV, et al. Graft materials in oral surgery: revision. J Biomimetics Biomater Tissue Eng. 2014;19:124.

13. Kumar P, et al. Bone grafts in dentistry. J Pharm Bioallied Sci. 2013;5(Suppl 1):S125-7.

14. Laurencin C, Khan Y, El-Amin SF. Bone graft substitutes. Expert Rev Med Devices. 2006;3:49-57.

15. Giannoudis PV, Dinopoulos H, Tsiridis E. Bone substitutes: an update. Injury. 2005;36(Suppl 3):S20-7.

16. Conrad EU, Gretch DR, Obermeyer KR, Moogk MS, Sayers M, Wilson JJ, et al. Transimission of the hepatitis-C virus by tissue transplantation. J Bone Joint Surg Am. 1995;77:214-24.

17. Centres for disease control and prevention. Septic arthritis following anterior cruciate ligament reconstruction using tendon allografts: Florida and Louisiana, 2000. MMWR Morb Mortal Wkly Rep. 2001;50:1081-3.

18. Boyne PJ, Sands NR. Secondary bone grafting of residual alveolar and palatal clefts. J Oral Surg. 1972 Feb;30(2):87-92.

19. Meara DJ. Acquired defects of the nose and naso-orbitoethmoid (NOE) region. Oral Maxillofac Surg Clin North Am. 2013;25(2):131-49.

20. Rieck KL, Fillmore WJ, Ettinger KS. Late revision or correction of facial trauma-related soft-tissue deformities. Oral Maxillofac Surg Clin North Am. 2013;25(4):697-713.

21. Khorasani M, et al. Maxillofacial reconstruction with Medpor porous polyethylene implant: a case series study. J Korean Assoc Oral Maxillofac Surg. 2018;44(3):128-35.

22. Schwaiger M, Echlin K, Atherton D, Haers P. The use of Medpor implants for midface contouring in cleft patients. Int $\mathbf{J}$ Oral Maxillofac Surg. 2019.

23. Scolozzi P. Maxillofacial reconstruction using polyetheretherketone patient-specific implants by "mirroring" computational planning. Aesthet Plast Surg. 2012;36(3):660-5.

24. Kim MM, Boahene KDO, Byrne PJ. Use of customized polyetheretherketone (PEEK) Implants in the reconstruction of complex maxillofacial defects. Arch Facial Plast Surg. 2009;11(1): 53-7.

25. Salomon D, Miloro M, Kolokythas A. Outcomes of immediate allograft reconstruction of long span defects of the inferior alveolar nerve. J Oral Maxillofac Surg. 2016.

26. Bagheri SC, Meyer RA, Khan HA, Steed MB. Microsurgical repair of peripheral trigeminal nerve injuries from maxillofacial trauma. J Oral Maxillofac Surg. 2009;67(9):1791-9. 
27. Renzi G, Carboni A, Perugini M, et al. Posttraumatic trigeminal nerve impairment: A prospective analysis of recovery patterns in a series of 103 consecutive facial fractures. J Oral Maxillofac Surg. 2004;62:1341.

28. Thurmuller P, Dodson TB, Kaban LB. Nerve injuries associated with facial trauma: Natural history, management, and outcomes of repair. Oral Maxillofac Surg Clin North Am. 2001;13:283.

29. Meyer RA. Nerve harvesting procedures. Atlas Oral Maxillofac Surg Clin North Am. 2001;9:77.

30. Joohee J, et al. Per-oral cross-facial sural nerve graft for facial reanimation. Maxillofac Plast Reconstr Surg. 2018;40(1):22.

31. Lu X, Cai Z, Peng X, Yu G. Reconstruction of peripheral facial nerve injury. Int J Oral Maxillofac Surg. 2009;38(5):511.

32. Ichihara S, Inada Y, Nakamura T. Artificial nerve tubes and their application for repair of peripheral nerve injury: an update of current concepts. Injury. 2008;39(Suppl 4):29-39.

33. Gheisari R, et al. Parotid duct repair by facial vein graft versus gore-tex: a sialographic evaluation. J Dent (Shiraz, Iran). 2013;14(2):53-6.

34. Raveenthiran V. Reconstruction of traumatically avulsed parotid duct using buccal mucosa flap: report of a new technique. J Trauma. 2008;65:732-5.

35. Lewkowicz AA, Hasson O, Nahlieli O. Traumatic injuries to the parotid gland and duct. J Oral Maxillofac Surg. 2002;60:676-80.

36. Parekh D, Glezerson G, Stewart M, Esser J, Lawson HH. Posttraumatic parotid fistulae and sialoceles. A prospective study of conservative management in 51 cases. Ann Surg. 1989;209:105-11.

37. Ananthakrishnan N. Vein graft repair of a chronic parotid duct fistula. J Oral Maxillofac Surg. 1983;41:266-7.

38. Heymans O, Nélissen X, Médot M, Fissette J. Microsurgical repair of Stensen's duct using an interposition vein graft. J Reconstr Microsurg. 1999;15:105-7.

39. Tao JP, Luppens D, McCord CD. Buccal mucous membrane graftassisted lacrimal drainage surgery. Ophthalmic Plast Reconstr Surg. 2010;26(1):39-41.

40. Balaji SM. Management of nasolacrimal duct injuries in midfacial advancement. Ann Maxillofac Surg. 2015;5(1):93-5.

41. Tao H, Wu H-Y, Hou S-K. Lacrimal duct reconstruction with grafting of great saphenous vein or labial mucosa via endoscopic transnasal dacryocystorhinostomy: a group comparison in 18 cases. J Clin Rehabil Tissue Eng Res. 2009;13(44):8797-800.

42. Terino EO, Edwards MC. Customizing jawlines: the art of alloplastic premandible contouring. Facial Plast Surg Clin North Am. 2008;16:99-122.

43. Scolozzi P, Martinez A, Jaques B. Complex orbitofrontotemporal reconstruction using computer-designed PEEK implant. J Craniofac Surg. 2007;18:224-8.

\section{Hard Tissue Deformities}

44. Van der Meulen JC. Medial faciotomy. Br J Plast Surg. 1979;32:339-42.

45. Hupp JR, Tucker MR, Ellis E. Surgical reconstruction of defects of jaw. Contemporary oral and maxillofacial surgery, 7th ed. 2019 p. $628-40$

46. Vega LG. Reoperative mandibular trauma: management of posttraumatic mandibular deformities. Oral Maxillofac Surg Clin North Am. 2011;23(1):47-61, v-vi.

47. Haug RH, Schwimmer A. Fibrous union of the mandible: a review of 27 patients. J Oral Maxillofac Surg. 1994;52(8):832-9.
48. Mathog RH, Toma V, Clayman L, et al. Nonunion of the mandible: an analysis of contributing factors. J Oral Maxillofac Surg. 2000;58(7):746-52.

49. Furr AM, Schweinfurth JM, May WL. Factors associated with long-term complications after repair of mandibular fractures. Laryngoscope. 2006;116(3):427-30.

50. De Souza M, Oeltjen JC, Panthaki ZJ, et al. Posttraumatic mandibular deformities. J Craniofac Surg. 2007;18(4):912-6.

51. Ellis E. Complications of rigid internal fixation for mandibular fractures. J Craniomaxillofac Trauma. 1996;2(2):32-9.

52. Koury M. Complications of mandibular fractures. In: Kaban L, Pogrel A, Perrott D, editors. Complications in oral and maxillofacial surgery. 1st ed. Philadelphia: WB Saunders; 1997. p. 121-45.

53. Ellis E, Walker R. Treatment of malocclusion and TMJ dysfunction secondary to condylar fractures. Craniomaxillofac Trauma Reconstr. 2009;2(1):1-18.

54. Laskin DM. Management of condylar process fractures. Oral Maxillofac Surg Clin North Am. 2009;21(2):193-6.

55. Becking AG, Zijderveld SA, Tuinzing DB. Management of posttraumatic malocclusion caused by condylar process fractures. J Oral Maxillofac Surg. 1998;56(12):1370-4.

56. Ellis E, Throckmorton G. Treatment of mandibular condylar process fractures: biological considerations. J Oral Maxillofac Surg. 2005;63(1):115-34.

57. Marx RE, Saunders TR. Reconstruction and rehabilitation of cancer patients. In: Fonseca RJ, Davis WH, editors. Reconstructive preprosthetic oral and maxillofacial surgery. Philadelphia, PA: WB Saunders; 1986.

58. Acero J, García E. Reoperative midface reconstruction. Oral Maxillofac Surg Clin North Am. 2011;23(1):133-51, vii.

59. Kokemueller H, Tavassol F, Ruecker M, et al. Complex midfacial reconstruction: a combined technique of computer-assisted surgery and microvascular tissue transfer. J Oral Maxillofac Surg. 2008;66:2398-406.

60. Zizelmann C, Gellrich NC, Metzger MC, et al. Computer-assisted reconstruction of orbital floor based on cone beam tomography. $\mathrm{Br}$ J Oral Maxillofac Surg. 2007;45(1):79-80.

61. Coleman SR. Facial recontouring with lipostructure. Clin Plast Surg. 1997;24:347-67.

62. Wassmund M. Lehrbuch der praktischen Chirurgie 6es Mundes und der Ki.efer, Bd. I. Meusser, Leipzig 1935

63. Wunderer S. Die Prognathieoperation mittels frontal gestieltem Maxillafragment. Ost Z Stomat. 1962;59:98.

64. Schuchardt K. Formen des offenen Bisses und ihre operativen Behandlungsmöglichkeiten. Fortschr Kiefer Gesichtschir. 1955;1:222-30.

65. Tessier P, Guiot G, Rougerie J, Delbet JP, Pastoriza J. Cranionaso-orbito-facial osteotomies. Hypertelorism. Ann Chir Plast. 1967;12:103-18.

66. Tessier P. Total facial osteotomy. Crouzon's syndrome, Apert's syndrome: oxycephaly, scaphocephaly, turricephaly. Ann Chir Plast. 1967; 12:273-86.

67. Tessier P. Experiences in the treatment of orbital hypertelorism. Plast Reconstr Surg. 1974;53:1-18.

68. Converse JM, Ransohoff J, Mathews ES, Smith B, Molenaar A. Ocular hypertelorism and pseudohypertelorism. Advances in surgical treatment. Plast Reconstr Surg. 1970;45:1-13.

69. Van der Meulen JC, Vaandrager JM. Surgery related to the correction of hypertelorism. Plast Reconstr Surg. 1983;71:6-19.

70. Ortiz-Monasterio F, del Campo AF, Carrillo A. Advancement of the orbits and the midface in onepiece, combined with frontal 
repositioning, for the correction of Crouzon's deformities. Plast Reconstr Surg. 1978;61:507-16.

71. Marchac D, Renier D, Arnaud E. Infrafrontal correction of teleorbitism. In: Whitaker L, editor. Proceedings from the seventh meeting of the ISCFS. Santa Fe: Menduzzi; 1997. p. 173-5.

72. Marin PC, Love T, Carpenter R, Iliff NT, Manson PN. Complications of orbital reconstruction: misplacement of bone grafts within the intramuscular cone. Plast Reconstr Surg. 1998;101:1323-7.

73. Wolff J, Sándor GK, Pyysalo M, Miettinen A, Koivumäki $\mathrm{AV}$, Kainulainen VT. Late reconstruction of orbital and nasoorbital deformities. Oral Maxillofac Surg Clin North Am. 2013;25(4):683-95.

74. Cohen SR, Kawamoto HK Jr. Analysis and results of treatment of established posttraumatic facial deformities. Plast Reconstr Surg. 1992;90:574-84.

75. Sandor GK, Clokie CM. Hypertelorism. In: Fonseca RJ, editor. Oral and maxillofacial surgery, vol. 6. Philadelphia: W.B. Saunders Company; 2000. p. 221-38.

76. Tessier P. Anatomical classification of facial, craniofacial, and latero-facial clefts. J Maxillofac Surg. 1976;4:69-89.

77. Lanigan DT, Stoelinga PJ. Fractures of the supraorbital rim. J Oral Surg. 1980;38(10):764-70.

\section{Post Oncological Deformities}

78. Hurvitz KA, Kobayashi M, Evans GR. Current options in head and neck reconstruction. Plast Reconstr Surg. 2006;118(5): $122 \mathrm{e}-33 \mathrm{e}$

79. Renner G. Reconstruction of the lip. In: Baker S, editor. Local flaps in facial reconstruction. 2nd ed. Philadelphia, PA: Mosby; 2007. p. 475-525.

80. Abbe R. A new plastic operation for the relief of deformity due to double harelip. Plast Reconstr Surg. 1968;42(5):481-3.

81. Ong WC, Lim J, Lim TC. A modification of the bilobed and Karapandzic flap used for reconstruction of the lower lip. Plast Reconstr Surg. 2005;115(7):2154-5.

82. Anvar BA, Evans BC, Evans GR. Lip reconstruction. Plast Reconstr Surg. 2007;120(4):57e-64e.

83. Ozdemir R, Ortak T, Kocer U, Celebioglu S, Sensoz O, Tiftikcioglu YO. Total lower lip reconstruction using sensate composite radial forearm flap. J Craniofac Surg. 2003;14(3):393-405.

84. McConnel FM, Pauloski BR, Logemann JA, Rademaker AW, Colangelo L, Shedd D, et al. Functional results of primary closure vs flaps in oropharyngeal reconstruction: a prospective study of speech and swallowing. Arch Otolaryngol Head Neck Surg. 1998;124(6):625-30.

85. Yu P. Characteristics of the anterolateral thigh flap in a Western population and its application in head and neck reconstruction. Head Neck. 2004;26(9):759-69.
86. Vos JD, Burkey BB. Functional outcomes after free flap reconstruction of the upper aerodigestive tract. Curr Opin Otolaryngol Head Neck Surg. 2004;12(4):305-10.

87. Aziz SR. Andy Gump and his deformity. J Oral Maxillofac Surg. 2010 Mar;68(3):651-3.

88. Genden EM, Wallace D, Buchbinder D, Okay D, Urken ML. Iliac crest internal oblique osteomusculocutaneous free flap reconstruction of the postablative palatomaxillary defect. Arch Otolaryngol Head Neck Surg. 2001;127(7):854-61.

89. Rieger JM, Zalmanowitz JG, Li SY, Sytsanko A, Harris J, Williams D, et al. Functional outcomes after surgical reconstruction of the base of tongue using the radial forearm free flap in patients with oropharyngeal carcinoma. Head Neck. 2007;29(11): 1024-32.

90. Seikaly H, Rieger J, Wolfaardt J, Moysa G, Harris J, Jha N. Functional outcomes after primary oropharyngeal cancer resection and reconstruction with the radial forearm free flap. Laryngoscope. 2003;113(5):897-904.

91. Kolokythas A. Long-term surgical complications in the oral cancer patient: a comprehensive review. Part II. J Oral Maxillofac Res. 2010;1(3):e2.

92. Kim DD, Ord RA. Complications in the treatment of head and neck cancer. Oral Maxillofac Surg Clin North Am. 2003;15(2):213-27.

93. Friess CC, Fontaine DJ, Kornblut AD. Complications of therapy for oral malignant disease. Otolaryngol Clin $\mathrm{N}$ Am. 1979;12(1):175-81.

94. Ramon Y, Hendler S, Oberman M. A stepped technique for splitting of the lower lip. J Oral Maxillofac Surg. 1984;42(10): 689-91.

95. Lewis VL Jr, Manson PN, Stalnecker MC. Some ancillary procedures for correction of depressed adherent tracheostomy scars and associated tracheocutaneous fistulae. J Trauma. 1987;27(6): $651-5$.

96. Waldron J, Padgham ND, Hurley SE. Complications of emergency and elective tracheostomy: a retrospective study of 150 consecutive cases. Ann R Coll Surg Engl. 1990;72(4):218-20.

97. Hayter JP, Vaughan ED, Brown JS. Aesthetic lip splits. Br J Oral Maxillofac Surg. 1996;34(5):432-5.

98. Haug SP. Maxillofacial prosthetic management of the maxillary resection patient. Atlas Oral Maxillofac Surg Clin North Am. 2007;15(1):51-68.

99. Shah JP, Candela FC, Poddar AK. The patterns of cervical lymph node metastases from squamous carcinoma of the oral cavity. Cancer. 1990;66(1):109-13.

100. Kerawala CJ. Complications of head and neck cancer surgeryprevention and management. Oral Oncol. 2010;46(6):433-5.

101. Kolokythas A. Long-term surgical complications in the oral cancer patient: a comprehensive review. Part I. J Oral Maxillofac Res. 2010;1(3):e1

102. Cappiello J, Piazza C, Nicolai P. The spinal accessory nerve in head and neck surgery. Curr Opin Otolaryngol Head Neck Surg. 2007;15(2):107-11. 
103. Saunders JR Jr, Hirata RM, Jaques DA. Considering the spinal accessory nerve in head and neck surgery. Am J Surg. 1985;150(4): 491-4.

104. Schauber MD, Fontenelle LJ, Solomon JW, Hanson TL. Cranial/ cervical nerve dysfunction after carotid endarterectomy. J Vasc Surg. 1997;25(3):481-7.

105. Dingman RO, Grabb WC. Surgical anatomy of the mandibular ramus of the facial nerve based on the dissection of 100 facial halves. Plast Reconstr Surg Transplant Bull. 1962;29: 266-72.

\section{Recent Advances: Endoscopy in Management of Residual Deformities}

106. Pedroletti F, Johnson BS, McCain JP. Endoscopic techniques in oral and maxillofacial surgery. Oral Maxillofac Surg Clin North Am. 2010;22(1):169-82.

107. Gupta N. Endoscopic septoplasty. Indian J Otolaryngol Head Neck Surg. 2005;57(3):240-3.

Open Access This chapter is licensed under the terms of the Creative Commons Attribution 4.0 International License (http://creativecommons. org/licenses/by/4.0/), which permits use, sharing, adaptation, distribution and reproduction in any medium or format, as long as you give appropriate credit to the original author(s) and the source, provide a link to the Creative Commons license and indicate if changes were made.

The images or other third party material in this chapter are included in the chapter's Creative Commons license, unless indicated otherwise in a credit line to the material. If material is not included in the chapter's Creative Commons license and your intended use is not permitted by statutory regulation or exceeds the permitted use, you will need to obtain permission directly from the copyright holder. 